\title{
A Molecular Half-Wave Rectifier
}

\section{Citation}

Nijhuis, Christian A., William F. Reus, Adam C. Siegel, and George M. Whitesides. 2011. 'A

Molecular Half-Wave Rectifier." Journal of the American Chemical Society 133, no. 39: 1539715411.

\section{Published Version}

doi:10.1021/ja201223n

\section{Permanent link}

http://nrs.harvard.edu/urn-3:HUL.InstRepos:12967809

\section{Terms of Use}

This article was downloaded from Harvard University's DASH repository, and is made available under the terms and conditions applicable to Open Access Policy Articles, as set forth at http:// nrs.harvard.edu/urn-3:HUL.InstRepos:dash.current.terms-of-use\#OAP

\section{Share Your Story}

The Harvard community has made this article openly available.

Please share how this access benefits you. Submit a story.

Accessibility 


\section{A Molecular Half-Wave Rectifier}

Christian A. Nijhuis, ${ }^{1,{ }^{*}}$ William F. Reus, ${ }^{2}$ Adam C. Siegel, ${ }^{2}$ and George M. Whitesides ${ }^{2, *}$

${ }^{1}$ Department of Chemistry, National University of Singapore, 3 Science Drive 3,

Singapore 117543

${ }^{2}$ Department of Chemistry and Chemical Biology, Harvard University

Cambridge, MA 02138 U.S.A.

* Co-corresponding authors:

Tel.: 6174589430

Fax.: 6174589857

e-mail: gwhitesides@gmwgroup.harvard.edu

Tel.: +6565162667

Fax.: +65 67791691

e-mail: chmnca@nus.edu.sg

Abstract: This paper describes the performance of junctions based on self-assembled monolayers (SAMs) as the functional element of a half-wave rectifier (a simple circuit that converts, or rectifies, an AC signal to a DC signal). Junctions with SAMs of 11(ferrocenyl)-1-undecanethiol $\left(\mathrm{SC}_{11} \mathrm{Fc}\right)$ or 11-(biferrocenyl)-1-undecanethiol $\left(\mathrm{SC}_{11} \mathrm{Fc}_{2}\right)$ on ultra-flat, template-stripped $\mathrm{Ag}\left(\mathrm{Ag}^{\mathrm{TS}}\right)$ bottom-electrodes, and contacted by topelectrodes of eutectic indium-gallium (EGaIn), rectified AC signals, while similar junctions based on SAMs of 1-undecanethiol $\left(\mathrm{SC}_{10} \mathrm{CH}_{3}\right)$ - SAMs lacking the ferrocenyl 
terminal group - did not. SAMs in these AC circuits (operating at $50 \mathrm{~Hz}$ ) remain stable over a larger window of applied bias than in DC circuits. AC measurements, therefore, can investigate charge transport in SAM-based junctions at magnitudes of bias inaccessible to DC measurements. For junctions with SAMs of alkanethiols, combining the results from AC and DC measurements indentifies two regimes of bias with different mechanisms of charge transport: i) low bias $(|V|<1.3 \mathrm{~V})$, at which direct tunneling dominates, and ii) high bias $(|V|>1.3 \mathrm{~V})$, at which Fowler-Nordheim (FN) tunneling dominates. For junctions with SAMs terminated by Fc moieties, the transition to FN tunneling occurs at $|V|=\sim 2.0 \mathrm{~V}$. Furthermore, at sufficient forward bias $(V>0.5 \mathrm{~V})$, hopping makes a significant contribution to charge transport, and occurs in series with direct tunneling $(V<\sim 2.0 \mathrm{~V})$ until FN tunneling activates $(V>\sim 2.0 \mathrm{~V})$. Thus, for Fcterminated SAMs at forward bias, three regimes are apparent: i) direct tunneling $(V=0-$ $0.5 \mathrm{~V})$, ii) hopping plus direct tunneling $(V=0.5-\sim 2.0 \mathrm{~V})$, and iii) FN tunneling $(V>\sim$ $2.0 \mathrm{~V}$ ). Since hopping does not occur at reverse bias, only two regimes are present over the measured range of reverse bias. This difference in the mechanisms of charge transport at forward and reverse bias for junctions with Fc moieties resulted in large rectification ratios $(R>100)$ and enabled half-wave rectification.

\section{Introduction}

The field of molecular electronics applies the techniques and principles derived from studying inorganic electronic devices to investigating charge transport in organic molecules. While electrical engineers routinely use both alternating current (AC) and direct current (DC) to characterize traditional semiconductor devices, researchers in 
molecular electronics have, so far, relied solely on DC measurements. Here, we show that using AC signals to investigate charge transport in self-assembled monolayers (SAMs) yields new information, including information that could not be obtained using DC signals alone, and provides a straightforward means of comparing the performance of molecular diodes against that of diodes based on traditional semiconductor technology.

This paper describes half-wave rectification of $\mathrm{AC}(50 \mathrm{~Hz})$ signals by junctions based on SAMs. These junctions comprised SAMs of 11-(ferrocenyl)-1-undecanethiol ( $\left.\mathrm{SC}_{11} \mathrm{Fc}\right)$ or 11-(biferrocenyl)-1-undecanethiol $\left(\mathrm{SC}_{11} \mathrm{Fc}_{2}\right)$, supported on template-stripped $\mathrm{Ag}\left(\mathrm{Ag}^{\mathrm{TS}}\right)$ bottom-electrodes, and contacted by top-electrodes of eutectic indium-gallium (EGaIn, $75.5 \% \mathrm{Ga}$ and $24.5 \%$ In by weight, $15.7^{\circ} \mathrm{C}$ melting point, with a superficial layer of $\mathrm{Ga}_{2} \mathrm{O}_{3}$; Figure 1). ${ }^{1,2}$ Similar junctions based on SAMs of 1-undecanethiol $\left(\mathrm{SC}_{10} \mathrm{CH}_{3}\right)$ - SAMs lacking the ferrocenyl terminal group - did not rectify AC signals.

Previous experiments conducted using a DC bias of $\pm 1.0 \mathrm{~V}$, and junctions based on SAMs of $\mathrm{SC}_{11} \mathrm{Fc}^{1}$ and $\mathrm{SC}_{11} \mathrm{Fc}_{2},{ }^{3}$ yielded rectification ratios, $R$ (defined by eq. $1: J=$ current density $\left(\mathrm{A} / \mathrm{cm}^{2}\right)$ and $V=$ voltage $\left.(\mathrm{V})\right)$, of greater than $10^{2}$. These high values of $R$ make it possible to conduct physical-organic studies to determine the mechanism(s) of charge transport across these SAMs. We show that these systems - which are, in fact "molecular diodes" - can substitute for conventional diodes in a simple circuit - a halfwave rectifier (Figure 1) - that converts an input AC signal into an output DC signal. ${ }^{4}$

$$
R \equiv|J(-1.0 \mathrm{~V})| /|J(+1.0 \mathrm{~V})|
$$

These molecular diodes, indeed, provide the basis for half-wave rectifiers. The circuits were stable for 30-40 min of operation, at a frequency of $50 \mathrm{~Hz}$; this interval 
Figure 1: Schematic representations of the A) $\left.\mathrm{Ag}^{\mathrm{TS}}-\mathrm{SC}_{11} \mathrm{Fc}_{2} / / \mathrm{Ga}_{2} \mathrm{O}_{3} / \mathrm{EGaIn}, \mathrm{B}\right) \mathrm{Ag}^{\mathrm{TS}}$ $\mathrm{SC}_{11} \mathrm{Fc} / / \mathrm{Ga}_{2} \mathrm{O}_{3} / \mathrm{EGaIn}$, and C) $\mathrm{Ag}^{\mathrm{TS}}-\mathrm{SC}_{10} \mathrm{CH}_{3} / / \mathrm{Ga}_{2} \mathrm{O}_{3} / \mathrm{EGaIn}$ junctions, consisting of a $\mathrm{Ag}^{\mathrm{TS}}$ bottom-electrode, and a cone-shaped $\mathrm{Ga}_{2} \mathrm{O}_{3} / \mathrm{EGaIn}$ top-electrode. These diagrams represent "ideal" junctions. Real junctions have defects (see text for details). D) The circuit with the molecular junction as the diode in series with a resistor (1.5 M $\Omega$ ) and an AC signal generator. The circuit shows that the silver bottom-electrode is biased. An oscilloscope simultaneously measures both $V_{\text {in }}$ (the voltage applied by the signal generator) and $V_{\text {out }}$ (the voltage across the resistor). E) A screen-image of the oscilloscope with a junction of the type of $\mathrm{Ag}^{\mathrm{TS}}-\mathrm{SC}_{11} \mathrm{Fc} / / \mathrm{Ga}_{2} \mathrm{O}_{3} / \mathrm{EGaIn}$ in operation as a half-wave rectifier (the amplitude of sinusoidal input signal $V_{\text {in }}=2.0 \mathrm{~V}$ with a frequency of $50 \mathrm{~Hz})$. 

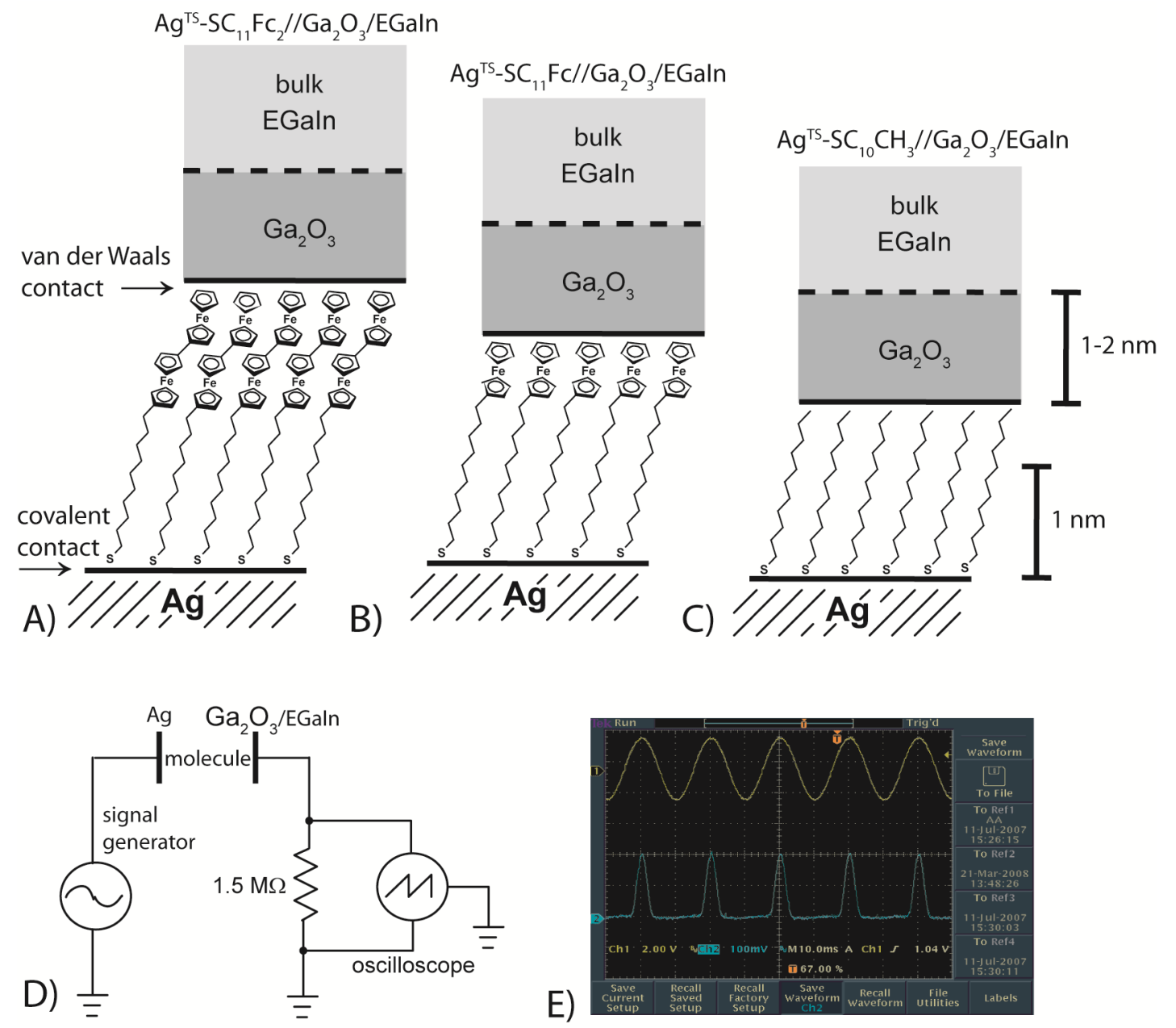
corresponds to more than $10^{5}$ cycles. At low frequencies $(\sim 1 \mathrm{~Hz})$, and at large input voltages ( $\sim 5 \mathrm{~V}$ for $\mathrm{SC}_{11} \mathrm{Fc}$ and $\sim 10 \mathrm{~V}$ for $\mathrm{SC}_{11} \mathrm{Fc}_{2}$, see the "Results and Discussion" section) the junctions broke down more rapidly (typically after $10^{2}-10^{3}$ cycles). In both circumstances the circuits failed by shorting across the SAM.

Using AC signals made it possible to study the mechanisms of charge transfer across the junctions as a function of potential over a much wider potential window (effective potentials across the junctions (see below for details) ranging from -5.0 to 2.2 $\mathrm{V}$ for $\mathrm{SC}_{11} \mathrm{Fc}_{2},-4.0$ to $2.2 \mathrm{~V}$ for $\mathrm{SC}_{11} \mathrm{Fc}$, and -1.5 to $1.6 \mathrm{~V}$ for $\mathrm{SC}_{11}$ ) than using a $\mathrm{DC}$ signal (typically limited to $\pm 1.0 \mathrm{~V}$ ). Studying SAM-based junctions in these large potential windows allowed us to determine the breakdown voltages, and the practical limitations, of these molecular diodes, as well as to discriminate between tunneling, hopping, and field emission as mechanisms of charge transport.

Aviram and Ratner proposed in 1974 that molecules could act as diodes. ${ }^{5}$ Since then, a variety of molecular diodes have been claimed, $6,7,8,9,10,11$ including one example by us. ${ }^{12}$ In general, reports of these diodes assume that rectification is a consequence of molecular structure (especially the group dipole of the structure). The difficulty in making meaningful measurements across SAMs has, however, made it practically impossible to correlate mechanisms of charge transport and rectification with the molecular and supramolecular structure of the SAM. Five characteristics of SAM-based junctions have complicated these measurements. i) The molecular structures used in many studies have been unnecessarily complex..$^{13,14,15}$ ii) The observed rectification ratios have often been close to unity (and perhaps statistically indistinguishable from unity), ${ }^{16,17,18}$ including one example reported by us. ${ }^{12}$ iii) The reproducibility, yield, and 
operational lifetime of many of these systems have been low, or have not been reported. ${ }^{13}$ iv) Other asymmetries in the junction unrelated to the molecular component - for example, electrodes of different materials, or junctions with two different types of contacts of the SAM with electrodes - may have contributed to rectification (without a molecular origin). ${ }^{11,19}$ Cahen et al. ${ }^{20,21,22}$ showed that their Si-alkyl//Hg based junctions can give detailed information about the mechanisms of charge transport across these junctions, but it requires more experiments. v) Statistical analysis of the data involving rectification and studies of the stability of rectifying junctions, have been largely absent in the literature, ${ }^{1,3,23,24}$ it has, thus, been difficult to separate meaningful results from noise or artifacts. ${ }^{25,26,27}$ Here we show that rectifying junctions of the form $\mathrm{Ag}^{\mathrm{TS}}$ $\mathrm{SC}_{11} \mathrm{Fc} / / \mathrm{Ga}_{2} \mathrm{O}_{3} / \mathrm{EGaIn}$ and $\mathrm{Ag}^{\mathrm{TS}}-\mathrm{SC}_{11} \mathrm{Fc}_{2} / / \mathrm{Ga}_{2} \mathrm{O}_{3} / \mathrm{EGaIn}$ can be fabricated in good yields $(70-90 \%)$, are stable over thousands of cycles, and give reproducible $J(\mathrm{~V})$ results.

The junction at one bias is the reference for the junction at the opposite bias, because the value of $R$ is determined by dividing the current in on direction of bias by the current measured at the opposite direction (eq. 1) across the same junction. Studying the rectification ratios, thus, eliminates many of the uncertainties related to contact resistances or contact areas (although some effects unrelated to the SAM, such as dipoles at interfaces between different materials, may also cause rectification).

AC measurements offer three advantages over DC measurements for investigating molecular rectification. i) Using AC minimizes the formation of filaments by electromigration. ${ }^{28}$ Metal filaments can form in high electrical fields, especially when Ag electrodes are used, due to electromigration of atoms. ${ }^{29}$ ii) Using AC makes it possible to collect data rapidly: recording a $J(\mathrm{~V})$ curve by incrementally applying a DC bias usually 
takes several minutes, while recording the same curve with, for instance, an $\mathrm{AC}$ signal at $50 \mathrm{~Hz}$, takes $20 \mathrm{~ms}$. iii) Using AC makes it possible to incorporate a resistor in series with the molecular tunneling junction and effectively places an upper bound on the potential drop across the junction and protects against breakdown.

Rectifying SAM-based tunneling junctions have not been subjected to the sort of characterization in simple circuitry that is routine for diodes based on inorganic components, although such characterization is essential to determining the operational mechanisms and parameters - and thus the usefulness - of SAM-based rectifiers in electronic applications. This paper yields four important conclusions. i) At high voltages across the SAM $(V>\sim 2.0 \mathrm{~V})$ the SAM-based junctions have a mechanism of charge transport (field emission) that is different from the mechanism at low voltages (hopping and tunneling). ${ }^{30}$ The half-wave rectifier (Figure 1D) incorporating these molecular diodes rectifies at input voltages less than $2.4 \mathrm{~V}$, but does not rectify at high input voltages in the range of $2.4-10 \mathrm{~V}$ (these voltages are specific to the circuit and depend on the choice of resistor). ii) In operation, these molecular diodes have large internal resistances $\left(\sim 10^{6} \Omega\right)$, suffer limited lifetimes (here 30-40 min in operation at $50 \mathrm{~Hz}$ ), and break down outside of a relatively small window of applied bias (-5.0 to $2.2 \mathrm{~V})$. Reporting only values of $R$ for a molecular diode is insufficient to characterize its performance and establish its practical usefulness. iii) The breakdown voltages of the diodes determined using the $\mathrm{AC}$ method are a factor of two larger than those determined by DC methods. This result implies that AC signals, indeed, reduce the formation of metal filaments, or other possible side reactions, inside the SAM-based junctions. Thus, the method described in this paper provides both information about the practical utility 
and limitations of SAM-based diodes, and fundamental information about the mechanisms of charge transport. iv) The properties of these systems suggest them as excellent models with which to study the mechanisms of charge transport in organic matter, but do not show (so far) properties that indicate a potential advantage over conventional inorganic rectifiers in practical applications.

\section{Prior Work}

Junctions with Top-Electrodes of Cone-Shaped Tips of $\mathrm{Ga}_{2} \mathrm{O}_{3} / \mathbf{E G a I n}$. We have previously described the fabrication of junctions of the form $\mathrm{Ag}^{\mathrm{TS}}$ $\mathrm{SAM} / / \mathrm{Ga}_{2} \mathrm{O}_{3} / \mathrm{EGaIn}$ with SAMs of $\mathrm{n}$-alkanethiolates ${ }^{2}$ and ferrocene-terminated alkanethiolates ${ }^{1}$. This method produces stable, reproducible molecular tunneling junctions with bottom-electrodes of template-stripped $\mathrm{Ag}, \mathrm{Ag}^{\mathrm{TS}}$, and cone-shaped topelectrodes of $\mathrm{Ga}_{2} \mathrm{O}_{3} / \mathrm{EGaIn}$ suspended from a syringe. Although this system still requires an experienced operator, and substantial attention to detail, it can generate data with good reproducibility. ${ }^{1,3}$ This reproducibility, combined with the stability of these molecular junctions (they can withstand many cycles of applied bias, as well as small mechanical disturbances) enables their use in physical-organic studies measuring the effect of the composition and structure of the SAM on charge transport.

\section{The Influence of the Layer of $\mathrm{Ga}_{2} \mathrm{O}_{3}$ on the Characteristics of the Junctions.}

We have studied the influence of the layer of $\mathrm{Ga}_{2} \mathrm{O}_{3}$ on the $J(\mathrm{~V})$ characteristics of these SAM-based junctions. We concluded that the layer of $\mathrm{Ga}_{2} \mathrm{O}_{3}$ has a resistance that is at least three to four orders of magnitude smaller than a SAM of $\mathrm{SC}_{10} \mathrm{CH}_{3} \cdot{ }^{1,3,31} \mathrm{We}$ also found that the mechanism of charge transport across this layer is thermally activated. ${ }^{31}$ 
We believe that the influence of the layer of $\mathrm{Ga}_{2} \mathrm{O}_{3}$ on the electrical properties of these SAM based junctions is insignificant: the electrical properties of these junctions are dominated by the chemical and supramolecular structure of the SAM.

Detailed studies by secondary ion mass spectroscopy (ToF SIMS), scanning electron microscopy (SEM), and angle resolved X-ray photospectroscopy (ARXPS), indicated that the layer of gallium oxides: i) has an average thickness of $0.7 \mathrm{~nm}$, ii) has substantial roughness, iii) is mainly composed of $\mathrm{Ga}_{2} \mathrm{O}_{3}$, though $\mathrm{Ga}_{2} \mathrm{O}$ and $\mathrm{In}_{2} \mathrm{O}_{3}$ are present, and iv) supports a fibrous network of adsorbed organic material (the fraction of the surface covered by this network, and the chemical composition of the fibers may depend on the ambient conditions). ${ }^{32}$ This organic network is probably the least understood component of our system, and we are working to quantify or eliminate it, but it has not prevented us from obtaining meaningful results in controlled, physical-organic studies.

Using inverted optical microscopy, we observed that the visible contact area between the cone-shaped tip of $\mathrm{Ga}_{2} \mathrm{O}_{3} / \mathrm{EGaIn}$ and the SAM is $\sim 25 \%$ of the measured contact area. ${ }^{3,31,33}$ The (presumably normally distributed) uncertainty of estimating the actual contact area is, at present, not a dominant (and in many systems not even significant) component of the log-normally distributed uncertainty that we observe in $J(V)$ measurements.

We measured the electrical properties of the layer of $\mathrm{Ga}_{2} \mathrm{O}_{3}$ and concluded that, in a typical junction, the resistance of this layer is at least four orders of magnitude less than that of a SAM of $\mathrm{SC}_{10} \mathrm{CH}_{3} \cdot{ }^{3,31,33}$ Hence, we do not believe that the electrical properties of the layer of $\mathrm{Ga}_{2} \mathrm{O}_{3}$ significantly affect charge transport through SAM-based junctions. 
The low resistance of the layer of $\mathrm{Ga}_{2} \mathrm{O}_{3}$ fits with the observation that this layer contains many defects, which may dope the material and increase its conductivity. Theoretically, a defect-free, thin film of $\mathrm{Ga}_{2} \mathrm{O}_{3}$ should be insulating. ${ }^{34}$

Molecular Rectification by SAMs of $\mathrm{SC}_{11} \mathrm{Fc}$. We found that two characteristics of the $\mathrm{SAMs}$ of $\mathrm{SC}_{11} \mathrm{Fc}$ inside the junctions cause the large observed rectification ratios $\left(R \approx 1.0 \times 10^{2}\right.$, measured at $\pm 1.0 \mathrm{~V}, \mathrm{DC}$ measurements): i) the potential drop across the SAM is non-uniform because the SAM is asymmetric, ${ }^{3}$ and ii) the mechanism of charge transport changes from tunneling to hopping in only one direction of bias, and not in the other. $^{31}$

The SAMs of $\mathrm{SC}_{11} \mathrm{Fc}$ only rectify when the $\mathrm{Fc}$ moiety is located asymmetrically in the SAM: that is, the Fc moiety must be in close spatial proximity to one of the electrodes. In our junctions, the Fc moiety is in van der Waals contact with the $\mathrm{Ga}_{2} \mathrm{O}_{3} / \mathrm{EGaIn}$ top-electrode, but is separated from the $\mathrm{Ag}^{\mathrm{TS}}$ bottom-electrode by the $\mathrm{C}_{11}$ alkyl chain. ${ }^{3}$ Consequently, the HOMO of the Fc moiety follows the Fermi level of the top-electrode. The HOMO of the Fc is only energetically accessible when it overlaps with both Fermi levels, which, in our case, only is possible at negative bias, and not at positive bias. Figure 2 shows the energy level diagrams for the $\mathrm{Ag}^{\mathrm{TS}}-\mathrm{SC}_{11} \mathrm{Fc}_{\mathrm{c}} / \mathrm{Ga}_{2} \mathrm{O}_{3} / / \mathrm{EGaIn}$ junctions at a bias of $-1.0,0.0$, and $1.0 \mathrm{~V}$.

At sufficient negative bias, the $\mathrm{HOMO}$ of the $\mathrm{Fc}$ can participate in charge transport, and the potential drops mainly across the $\mathrm{C}_{11}$ alkyl chain. At positive bias, the HOMO of the Fc cannot participate in charge transport, and the potential drops more or less equally along the both the $\mathrm{C}_{11}$ and $\mathrm{Fc}$ moiety. The difference in the profile of the potential across the junction, at positive and negative bias, causes rectification. ${ }^{3}$ 
Figure 2: Schematic representation of the energy level diagrams (with respect to vacuum) of the $\mathrm{Ag}^{\mathrm{TS}}-\mathrm{SC}_{11} \mathrm{Fc} / / \mathrm{Ga}_{2} \mathrm{O}_{3} / \mathrm{EGaIn}$ junctions at $1.0 \mathrm{~V}$ (left), and $-1.0 \mathrm{~V}$ (right) bias. Ag-S denotes the covalent bond between the thiol and the $\mathrm{Ag}^{\mathrm{TS}}$ substrate, $\mathrm{C}_{11}$ denotes the alkyl chain, Fc denotes ferrocene, and vdW denotes the van der Waals contact of the SAM with the $\mathrm{Ga}_{2} \mathrm{O}_{3} / \mathrm{EGaIn}$. 


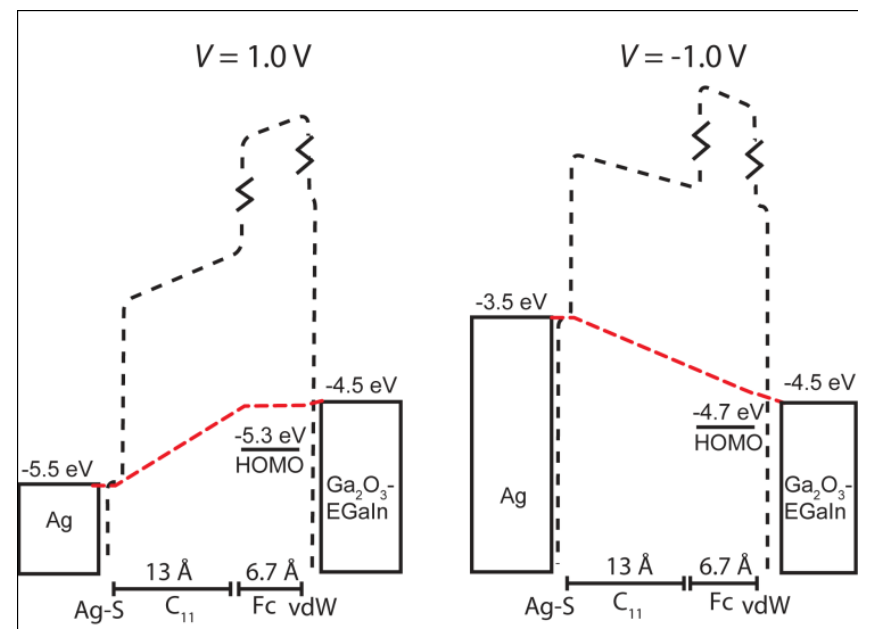


Measurement of $J(\mathrm{~V})$ as a function of temperature indicated that, at negative bias, when the HOMO of the Fc participates in charge transport, the mechanism of charge transport changes from tunneling (which is independent of $T$ ) to hopping (which is dependent on $T$ ), while at positive bias, when the HOMO can not participate in charge transport, the mechanism of charge transport is tunneling for all measured $T .^{31}$

This change in the mechanism of charge transport effectively reduces the width of the tunneling barrier in one direction of bias (but not the other) from $\sim 2.0 \mathrm{~nm}$ (the entire length of the $\mathrm{SC}_{11} \mathrm{Fc}$ molecule) to $\sim 1.3 \mathrm{~nm}$ (the length of the $\mathrm{SC}_{11}$ alkyl chain). Charges must, therefore, tunnel across a much wider barrier at reverse bias than at forward bias. This change in the width of the tunneling barrier results in the large observed rectification ratios of $1.0 \times 10^{2}$

Other Junctions with $\mathbf{S C}_{\mathbf{1 1}} \mathbf{F c}$. Zandvliet et al. ${ }^{35}$ showed, using a tungsten STM tip as a top-electrode, that molecules of $\mathrm{SC}_{11} \mathrm{Fc}$ inserted in $\mathrm{SAMs}_{\mathrm{A}} \mathrm{SC}_{11}$ on Au rectify currents with a rectification ration of about ten. The lower values of $R$ observed in their experiment could be caused by a lower density of $\mathrm{SC}_{11} \mathrm{Fc}$ in their $\mathrm{SAM}$, and/or the presence of an additional tunneling barrier - the vacuum gap between the SAM and the STM-tip - in their junctions. A second study reported a rectification ratio of 20 by contacting a monolayer of $\mathrm{SC}_{6} \mathrm{Fc}$ on Au with a Au-STM tip. ${ }^{36}$

We reported that tunneling junctions of $\mathrm{SAMs}$ of $\mathrm{SC}_{11} \mathrm{Fc}$ on $\mathrm{Ag}^{\mathrm{TS}}$ electrodes contacted with template-stripped Au foil (with a thickness of $50 \mathrm{~nm}$ ) rectified currents with values of $R$ of $10-100 .{ }^{3}$ Although these junctions were not stable enough to measure more than one - five traces, did not generate statistically large numbers of data, 
and gave low yields in working devices $(<10 \%)$, they showed that rectification in these SAMs is caused by the chemical structure of the SAM, and not by any of the other asymmetries in the junctions of $\mathrm{Ag}^{\mathrm{TS}}-\mathrm{SC}_{11} \mathrm{Fc} / / \mathrm{Ga}_{2} \mathrm{O}_{3} / \mathrm{EGaIn}$.

Mechanisms of Charge Transport Across SAMs. Three different mechanisms of charge transport across SAMs have been experimentally observed in SAM-based junctions: i) tunneling (both coherent and incoherent), ii) hopping, and iii) FowlerNordheim tunneling. ${ }^{30}$ Frisbie et al. ${ }^{37}$ showed that the mechanism of charge transport in junctions with conjugated molecular wires changes from tunneling to hopping as the molecular length increases. Used a conducting tip of an atomic force microscope as the top contact, they measured the conductivities of a series of oligophenyleneimines (OPI), with lengths ranging from 1.5 to $7.3 \mathrm{~nm}$, immobilized on gold bottom-electrodes. Their studies revealed that the dominant mechanism of charge transport across these junctions was tunneling for molecular wires shorter than $\sim 4 \mathrm{~nm}$, but the mechanism changed to hopping for molecular wires exceeding $\sim 4 \mathrm{~nm}$ in length. Beebe et al. ${ }^{38,39}$ showed that Fowler-Nordheim tunneling is important in SAM-based tunneling junctions above a critical voltage, the so-called transition voltage $\left(V_{\text {trans }}\right)$. Above the transition voltage, which depends on the shape and height of the tunneling barrier, the mechanism of charge transport changes from tunneling to Fowler-Nordheim tunneling.

Theory of the Mechanisms of Charge Transport: Tunneling. There is a broad consensus that the mechanism of charge transport across SAMs of n-alkanethiolates is coherent tunneling. ${ }^{40,41}$ The chemical and supramolecular structure defines the width of the tunneling barrier and the HOMO and LUMO levels define the height of this barrier. The mechanism of charge transport across these tunneling junctions is usually interpreted 
in terms of a model proposed by Simmons to describe tunneling through an inorganic insulator. $^{42,43}$ The model uses a generalized tunneling barrier - two metal electrodes separated by an insulator - with a trapezoidal shape under applied bias. As Simmons made clear, this model does not account for the image potential induced in the barrier by the electrodes. The image potential effectively rounds off the corners of the barrier and reduces its effective height and, consequently, increases the probability of tunneling. The Simmons equation also neglects a number of possibly other relevant features of SAMs, particularly their anisotropic structure and the dissimilarity of molecular orbitals to the electronic bands in inorganic materials.

A simple form of the Simmons equation (eq. 2) describes this barrier, where $J_{0}$ $\left(\mathrm{A} / \mathrm{cm}^{2}\right)$ is a constant and depends on the system and includes contact resistance, $d(\AA)$ is the width of the tunneling barrier, and the $\beta\left(\AA^{-1}\right)$ is the decay constant. Many groups have reported that tunneling through a SAM is more efficient $\left(\beta=0.80 \AA^{-1}\right)$ than through space $\left(\beta=2.9 \AA^{-1}\right.$ for a vacuum gap between two metals with work functions of $\left.5 \mathrm{eV}\right) .^{40}$ A generally accepted mechanism to explain the difference in values of $\beta$ in "insulating" media is super-exchange tunneling. ${ }^{44}$ Interactions of the electrons with the orbitals of the organic molecule increase the probability of tunneling, and make "through-bond" tunneling more efficient than "through-space" tunneling. ${ }^{45}$ No current theory, however, quantitatively predicts a value for $\beta=0.80 \AA^{-1}$.

$$
J=J_{0} e^{-\beta d}
$$

\section{Theory of the Mechanisms of Charge transport: Fowler-Nordheim}

Tunneling. Fowler-Nordheim tunneling, or field emission, is the emission of electrons under the influence of large electric fields from a metal, or semiconductor, into vacuum, 
or a dielectric. In SAM-based junctions, large electric fields $-1.0 \mathrm{~V}$ bias across a junction of $1 \mathrm{~nm}$ results in electric field of $1.0 \mathrm{GV} / \mathrm{m}$ - can cause emission of electrons from the electrodes to the SAM. Thus, the mechanism of charge transport changes from tunneling to Fowler-Nordheim tunneling with increasing electric field. Bebee et al. ${ }^{38,39}$ inferred that the Simmons theory can be used to determine the potential at which the mechanism of charge transport change from tunneling to field emission, or Fowler-Nordheim tunneling, when the barrier shape changes from rectangular to triangular when bias is applied.

Equation 3 gives the original form of the Simmons equation $(A=$ the junction area, $d=$ barrier width, $m_{\mathrm{e}}=$ the mass of the electron, $\Phi=$ barrier height, and $q=$ the electronic charge):

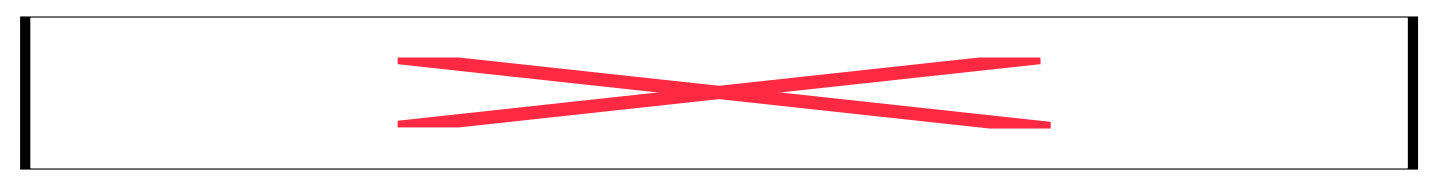

In molecular junctions the barrier width is defined by the molecular length and the barrier height corresponds to the energy offset between the Fermi-levels of the electrodes and the nearest molecular orbital, i.e., the LUMO levels of the alkyl groups and the $\mathrm{Fc}$ and $\mathrm{Fc}_{2}$ moieties. Beebe et al. ${ }^{38,39}$ described a method to estimate this barrier height. Near zero bias, the barrier shape is rectangular and eq. $\mathbf{3}$ reduces to eq. $\mathbf{4}$.

$$
I \propto V \exp \left(-\frac{2 d \sqrt{2 m_{e}} \phi}{\hbar}\right)
$$

In contrast, at the high-bias limit, the barrier shape changes from rectangular to triangular and the Simmons-like behavior is replaced by a Fowler-Nordheim dependence, which describes tunneling of electrons (holes) through a triangular barrier into the 
conduction (valence) band of an insulator or semiconductor, and subsequent field emission (eq. 5).

$$
I \propto V^{2} \exp \left(-\frac{4 d \sqrt{2 m_{e} \phi^{3}}}{3 \hbar q V}\right)
$$

Linearization of equation 5 gives eq. $\mathbf{6}^{38,39}$

$$
\ln \left(\frac{I}{V^{2}}\right) \propto-\frac{4 d \sqrt{2 m_{e} \phi^{3}}}{3 \hbar q}\left(\frac{1}{V}\right)
$$

According to eq. 6 , the slope of a plot of $\ln \left(I / V^{2}\right)$ versus $1 / V$ gives an estimate of the barrier height. In the low-bias limit, a plot of $\ln \left(I / V^{2}\right)$ versus $1 / V$ can be described by eq. 7..$^{38,39}$

$$
\ln \left(\frac{I}{V^{2}}\right) \propto-\ln \left(\frac{1}{V}\right)-\frac{2 d \sqrt{2 m_{e} \phi}}{\hbar}
$$

Equations 6 and 7 predict that a plot of $\ln \left(I / V^{2}\right)$ versus $1 / V$ will show a transition from logarithmic growth to linear decay ${ }^{38,39}$ Beebe et al. ${ }^{38,39}$ argued that a transition of the mechanism of charge transport from tunneling (logarithmic) to field emission (linear) would result in an inflection point in a plot of $\ln \left(I / V^{2}\right)$ versus $1 / V$. The potential at which this transition occurs is the so-called transition potential, $V_{\text {trans }}$. The Simmons equation does not take into account the potential drops across the contacts, or the image potentials, and the effective mass of the electrons crossing the junction may be different from the mass of an electron. Thus, a plot of $\ln \left(I / V^{2}\right)$ versus $1 / V$ only provides a first-order estimate of the barrier heights of the tunneling junctions.

\section{Experimental Design}


We reported the procedure for the analysis of the $\mathrm{J}(\mathrm{V})$ data obtained by $\mathrm{DC}$ methods before, but we give a short description here. ${ }^{1,3,31}$ Plotting histograms of all values of $|J|$ measured for a certain potential established that $|J|$ is log-normally distributed, i.e., $\log (|J|)$ is normally distributed. A log-normal distribution results from a randomly distributed variable whose logarithm is normally distributed. Thus, if variable $Y$ is normally distributed and $X$ depends exponentially on $Y$, i.e., $X \propto \mathrm{e}^{Y}$, then $\log X$ is normally distributed and $X$ is log-normally distributed. The value of $J$ depends exponentially on the distance $d$ between the top- and bottom-electrodes (eq. 2). We believe that $d$ is normally distributed; this distribution results in a log-normal distribution of the values of $J$.

We fitted histograms of $\log (|J|)$ with Gaussian functions, from which we determined the log-mean and log-standard deviation of $|J|$ at all measured potentials. These values were used to construct the average $J(\mathrm{~V})$ curves. We performed a similar analysis to determine the values for $R^{1,3,31}$

We used AC signals with a frequency of $50 \mathrm{~Hz}$ with amplitude ranging from 0.80 to $10.0 \mathrm{~V}$. We did not observe measurable output signals for input signals with an amplitude of $<0.80 \mathrm{~V}$ and the junctions shorted faster (after $10^{2}-10^{3}$ cycles) with input signals of $>5.0-10.0 \mathrm{~V}$.

We used a simple bread-board to connect the molecular junctions to the wave generator, oscilloscope, and resistor. This simple circuit was not free of capacitive currents; these were significant at frequencies of the input signal of $>100 \mathrm{~Hz}$. We found that at frequencies of $<10 \mathrm{~Hz}$ the junctions tended to short more rapidly. We choose to 
use a frequency of $50 \mathrm{~Hz}$ to minimize capacitive currents without compromising the lifetimes of the junctions during the experiments.

We used a large resistor $(1.5 \mathrm{M} \Omega)$ in series to the junction to minimize the currents across the junctions during the experiments; the purpose of this resistor was to limit the current through the tunneling junctions for the AC input signals with large amplitudes close to the breakdown voltages of the junction $(2-10 \mathrm{~V})$ when the resistance of the tunneling junction decrease significantly.

We used junctions of the form of $\mathrm{Ag}^{\mathrm{TS}}-\mathrm{SAM} / / \mathrm{Ga}_{2} \mathrm{O}_{3} / \mathrm{EGaIn}$ for three reasons. i) The template-stripped bottom-electrodes are ultra-flat. These electrodes have a surface roughness that is five times lower than bottom-electrodes obtained from direct metal deposition techniques. ${ }^{46}$ ii) The $\mathrm{SAMs}$ of $\mathrm{SC}_{11} \mathrm{Fc}$ give rectification ratios of two orders of magnitude. ${ }^{1,3,31}$ These high rectification ratios make it possible to conduct physicalorganic studies of charge transport. iii) The $\mathrm{Ga}_{2} \mathrm{O}_{3} / \mathrm{EGaIn}$ top-electrodes form stable contacts with the SAMs. ${ }^{1,2,31}$ This stability makes it possible to the electrical characteristics in the order of hours.

\section{Results and Discussion}

Current density measurements of the tunneling junctions. Figure 1 shows idealized schematic representations of the $\mathrm{Ag}^{\mathrm{TS}}-\mathrm{SC}_{11} \mathrm{Fc}_{2} / / \mathrm{Ga}_{2} \mathrm{O}_{3} / \mathrm{EGaIn}, \mathrm{Ag}^{\mathrm{TS}}$ $\mathrm{SC}_{11} \mathrm{Fc} / / \mathrm{Ga}_{2} \mathrm{O}_{3} / \mathrm{EGaIn}$, and $\mathrm{Ag}^{\mathrm{TS}}-\mathrm{SC}_{10} \mathrm{CH}_{3} / / \mathrm{Ga}_{2} \mathrm{O}_{3} / \mathrm{EGaIn}$ junctions. In reality, SAMs in these junctions have defects due to pinholes, step edges, etch pitches, phase domains, grains, grain boundaries, and impurities. ${ }^{47}$ We have described the $J(V)$ characteristics obtained with DC measurements, and detailed discussions of the possible defects in our 
tunneling junctions and their influence on the $J(\mathrm{~V})$ characteristics previously. ${ }^{1,2,3,31,46} \mathrm{We}$ developed a statistical procedure to measure the distribution of the valued of $J$, to discriminate real data form artifact, and to determine the yield of working devices and reproducibility. ${ }^{1,3,31}$

Figure 3 shows the $|J(\mathrm{~V})|$ curves (A-C) of the $\mathrm{Ag}^{\mathrm{TS}}{ }_{-} \mathrm{SC}_{11} \mathrm{Fc} / / \mathrm{Ga}_{2} \mathrm{O}_{3} / \mathrm{EGaIn}, \mathrm{Ag}^{\mathrm{TS}}-$ $\mathrm{SC}_{11} \mathrm{Fc}_{2} / / \mathrm{Ga}_{2} \mathrm{O}_{3} / \mathrm{EGaIn}$, and $\mathrm{Ag}^{\mathrm{TS}}-\mathrm{SC}_{10} \mathrm{CH}_{3} / / \mathrm{Ga}_{2} \mathrm{O}_{3} / \mathrm{EGaIn}$ junctions, along with the histograms of the value of $R$ obtained for each (D-F). Each point at a given voltage on the $|J(\mathrm{~V})|$ curve is the log-mean of all the (log-normally distributed) values of $|J|$ measured at that voltage and the error bars represent a factor of one log-standard deviation.

For each type of SAM, the Gaussian fit of $\log (R)$ to the histogram yielded the logmean $\left(\mu_{\log }\right)$ and log-standard deviation $\left(\sigma_{\log }\right)$, reported as $R=\mu_{\log }\left(\sigma_{\log }\right)$. The $\mathrm{Ag}^{\mathrm{TS}}$ $\mathrm{SC}_{10} \mathrm{CH}_{3} / / \mathrm{Ga}_{2} \mathrm{O}_{3} / E$ EaIn junctions only show a small value of $R=1.7$ (1.35). The higher values of currents appear at bias opposite to that for the $\mathrm{Ag}^{\mathrm{TS}}-\mathrm{SC}_{10} \mathrm{CH}_{3} / / \mathrm{Ga}_{2} \mathrm{O}_{3} / \mathrm{EGaIn}$ and $\mathrm{Ag}^{\mathrm{TS}}-\mathrm{SC}_{11} \mathrm{Fc}_{2} / / \mathrm{Ga}_{2} \mathrm{O}_{3} / \mathrm{EGaIn}$ junctions. A t-test for significance indicated that the small rectification ratio observed this junction is statistically different from unity. ${ }^{1}$ 
Figure 3: Log-average of the absolute current density $|J|$ plotted vs the voltage of the $\mathrm{Ag}^{\mathrm{TS}}-\mathrm{SC}_{11} \mathrm{Fc}_{2} / / \mathrm{Ga}_{2} \mathrm{O}_{3} /$ EGaIn junctions (25 junctions, 361 traces) (A), $\mathrm{Ag}^{\mathrm{TS}}$ $\mathrm{SC}_{11} \mathrm{Fc} / / \mathrm{Ga}_{2} \mathrm{O}_{3} / \mathrm{EGaIn}$ junctions (53 junctions, 997 traces) (B), and $\mathrm{Ag}^{\mathrm{TS}}$ $\mathrm{SC}_{10} \mathrm{CH}_{3} / / \mathrm{Ga}_{2} \mathrm{O}_{3} / \mathrm{EGaIn}$ junctions (23 junctions, 415 traces) $(\mathrm{C})$. The error bars represent the log-standard deviation. The histograms with a Gaussian fit of the $R$ of the $\mathrm{Ag}^{\mathrm{TS}}$ $\mathrm{SC}_{11} \mathrm{Fc}_{2} / / \mathrm{Ga}_{2} \mathrm{O}_{3} / \mathrm{EGaIn}$ junctions (D), $\mathrm{Ag}^{\mathrm{TS}}-\mathrm{SC}_{11} \mathrm{Fc} / / \mathrm{Ga}_{2} \mathrm{O}_{3} / \mathrm{EGaIn}$ junctions (E), and $\mathrm{Ag}^{\mathrm{TS}}-\mathrm{SC}_{10} \mathrm{CH}_{3} / / \mathrm{Ga}_{2} \mathrm{O}_{3} /$ EGaIn junctions (F) are also shown. $N_{\mathrm{R}}$ indicates the number of values of $R$ measured for a particular type of junction. The width of the distribution of $|J|$ for junctions with $\mathrm{C}_{10} \mathrm{CH}_{3}$ is reproducible across many studies, and strongly suggest that the widths of the distributions of $|J|$ for junctions with SAMs of $\mathrm{SC}_{11} \mathrm{Fc}$ and $\mathrm{SC}_{11} \mathrm{Fc}_{2}$ are due to (currently unidentified) features of the SAM, rather than the roughness of the $\mathrm{Ag}^{\mathrm{TS}}$ surface, the $\mathrm{Ag}^{\mathrm{TS}}$-SR interface, or the $\mathrm{R} / / \mathrm{Ga}_{2} \mathrm{O}_{3} / \mathrm{EGaIn}$ interface. 

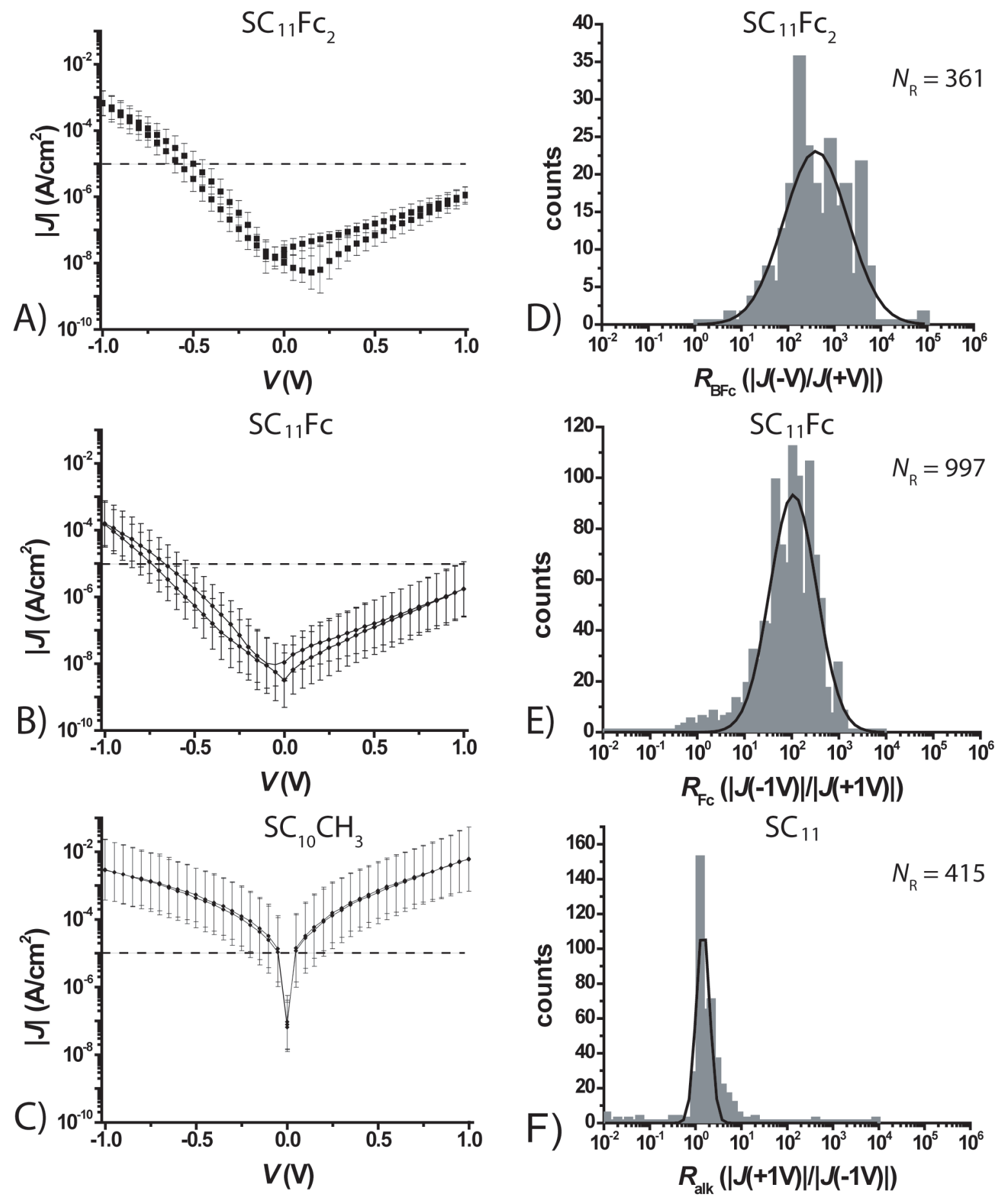
Table 1: Statistics of the $\mathrm{Ag}^{\mathrm{TS}}-\mathrm{SAM} / / \mathrm{Ga}_{2} \mathrm{O}_{3} / \mathrm{EGaIn}$ Junctions and Yields and Rectification Ratios.

\begin{tabular}{|c|c|c|c|c|c|c|c|}
\hline $\begin{array}{l}\text { Type of } \\
\text { SAM }\end{array}$ & $\begin{array}{l}\text { Total } \\
\text { substrates }\end{array}$ & $\begin{array}{l}\text { Total } \\
\text { junctions }\end{array}$ & $\begin{array}{l}\text { Total } \\
\text { traces in } \\
\text { histogram } \\
\end{array}$ & $\begin{array}{l}\text { short- } \\
\text { circuit } \\
\text { junctions }\end{array}$ & $\begin{array}{l}\text { Unstable } \\
\text { junctions }\end{array}$ & $\begin{array}{l}\text { Yield }^{\mathrm{c}} \\
(\%)\end{array}$ & $\begin{array}{l}\text { Rectification } \\
\text { ratio }^{\text {d }}\end{array}$ \\
\hline $\mathrm{SC}_{11} \mathrm{Fc}_{2}$ & 8 & 25 & 361 & $5(20 \%)$ & $3(12 \%)$ & 68 & $5.0 \times 10^{2}$ \\
\hline $\mathrm{SC}_{11} \mathrm{Fc}$ & 10 & 53 & 997 & $3(5.6 \%)$ & $4(7.4 \%)$ & 87 & $1.0 \times 10^{2}$ \\
\hline $\mathrm{SC}_{10} \mathrm{CH}_{3}$ & 4 & 23 & 415 & $4(17 \%)$ & $3(13 \%)$ & 70 & 1.7 \\
\hline
\end{tabular}

${ }^{\mathrm{a}} \mathrm{We}$ used ten different template-striped substrates from at least two wafers coated with $500 \mathrm{~nm}$ of Ag.

${ }^{\mathrm{b}}$ We formed the SAMs at the template-stripped Ag electrodes and contacted the SAMs with conically shaped electrodes of $\mathrm{Ga}_{2} \mathrm{O}_{3} / \mathrm{EGaIn}$ to complete the junctions.

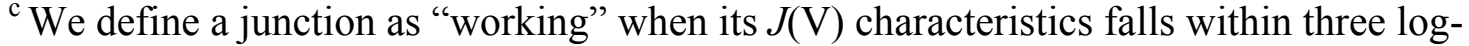
standard deviations from the mean value of $J$.

${ }^{\mathrm{d}}$ We determined these values of $R$ by DC measurements at $\pm 1.0 \mathrm{~V}$. 
Molecular Half-Wave Rectification of AC Potentials. The large rectification ratios of the junctions based on $\mathrm{Fc}$ - and $\mathrm{Fc}_{2}$-terminated SAMs make these attractive subjects for further investigation in simple circuits with AC signals (Fig. 1).

Figure 4 shows the measured input voltage, $V_{\text {in }}$ (black line), and the corresponding measured output voltage across the $1.5 \mathrm{M} \Omega$ resistor, $V_{\text {out }}$ (red line), of circuits containing junctions of $\mathrm{Ag}^{\mathrm{TS}}-\mathrm{SC}_{10} \mathrm{CH}_{3} / / \mathrm{Ga}_{2} \mathrm{O}_{3} / \mathrm{EGaIn}$ (Fig. $4 \mathrm{~A}$ ), $\mathrm{Ag}^{\mathrm{TS}}-\mathrm{SC}_{11} \mathrm{Fc} / / \mathrm{Ga}_{2} \mathrm{O}_{3} / \mathrm{EGaIn}$ (Fig. 4B), and $\mathrm{Ag}^{\mathrm{TS}}-\mathrm{SC}_{11} \mathrm{Fc}_{2} / / \mathrm{Ga}_{2} \mathrm{O}_{3} / \mathrm{EGaIn}$ (Fig. 4C). The $V_{\text {in }}$ was a $50 \mathrm{~Hz}$ sinusoidal signal with a peak voltage, $V_{\text {peak,in, }}$ of $2.6 \mathrm{~V}$ for the $\mathrm{Ag}^{\mathrm{TS}}-\mathrm{SC}_{11} \mathrm{Fc}_{2} / / \mathrm{Ga}_{2} \mathrm{O}_{3} / \mathrm{EGaIn}$ junction, and 2.1 Vfor the $\mathrm{Ag}^{\mathrm{TS}}-\mathrm{SC}_{11} \mathrm{Fc} / / \mathrm{Ga}_{2} \mathrm{O}_{3} / \mathrm{EGaIn}$ and $\mathrm{Ag}^{\mathrm{TS}}-\mathrm{SC}_{10} \mathrm{CH}_{3} / / \mathrm{Ga}_{2} \mathrm{O}_{3} / \mathrm{EGaIn}$ junctions. The circuits containing SAMs with $\mathrm{Fc}$ or $\mathrm{Fc}_{2}$ termini showed half-wave rectification (i.e., only the positive half of the sinusoidal input wave is present in the output signal), while the circuit containing the $\mathrm{SAM}$ of $\mathrm{SC}_{11} \mathrm{CH}_{3}$ (and thus lacking the $\mathrm{Fc}$ or $\mathrm{Fc}_{2}$ moieties) did not rectify. In all cases, $V_{\text {out }}$ signal is not detectably phase-shifted relative to $V_{\text {in }}$, but the values of $V_{\text {out }}$ are significantly less than the values of $V_{\text {in }}$ (See below).

The fact that the $\mathrm{Ag}^{\mathrm{TS}}-\mathrm{SC}_{11} \mathrm{Fc}_{2} / / \mathrm{Ga}_{2} \mathrm{O}_{3} / \mathrm{EGaIn}$ and $\mathrm{Ag}^{\mathrm{TS}}-\mathrm{SC}_{11} \mathrm{Fc} / / \mathrm{Ga}_{2} \mathrm{O}_{3} / \mathrm{EGaIn}$ junctions function as half-wave rectifiers, while the $\mathrm{Ag}^{\mathrm{TS}}-\mathrm{SC}_{10} \mathrm{CH}_{3} / / \mathrm{Ga}_{2} \mathrm{O}_{3} / \mathrm{EGaIn}$ junctions do not, is in agreement with the $J(\mathrm{~V})$ curves shown in Figure 3. The $\mathrm{Ag}^{\mathrm{TS}}$ $\mathrm{SC}_{10} \mathrm{CH}_{3} / / \mathrm{Ga}_{2} \mathrm{O}_{3} / \mathrm{EGaIn}$ junctions have rectification ratio close to unity, while the $\mathrm{Ag}^{\mathrm{TS}}$ $\mathrm{SC}_{11} \mathrm{Fc}_{2} / / \mathrm{Ga}_{2} \mathrm{O}_{3} / \mathrm{EGaIn}$ and $\mathrm{Ag}^{\mathrm{TS}}-\mathrm{SC}_{11} \mathrm{Fc} / / \mathrm{Ga}_{2} \mathrm{O}_{3} / \mathrm{EGaIn}$ junctions have rectification ratios of $10^{2}-10^{3}$ and, thus, are expected to behave like a diode. 
Figure 4: Sinusoidal input signals $\left(V_{\text {in }}\right.$ black $)$ with the corresponding output signal ( $V_{\text {out; }}$; red). These are data are not smoothed; the noise-levels of the data are in the $\mathrm{mV}$ range (see Figure 6 for examples). The input signal is sinusoidal $(50 \mathrm{~Hz})$ with a peak voltage ( $\left.V_{\text {peak,in }}\right)$ of $2.1 \mathrm{~V}$ for the $\mathrm{Ag}^{\mathrm{TS}}-\mathrm{SC}_{10} \mathrm{CH}_{3} / / \mathrm{Ga}_{2} \mathrm{O}_{3} / \mathrm{EGaIn}(\mathrm{A})$, and $\mathrm{Ag}^{\mathrm{TS}}$ $\mathrm{SC}_{11} \mathrm{Fc} / / \mathrm{Ga}_{2} \mathrm{O}_{3} / \mathrm{EGaIn}$ junctions (B), and $2.6 \mathrm{~V}$ for the $\mathrm{Ag}^{\mathrm{TS}}-\mathrm{SC}_{11} \mathrm{Fc}_{2} / / \mathrm{Ga}_{2} \mathrm{O}_{3} / \mathrm{EGaIn}$ junctions. 

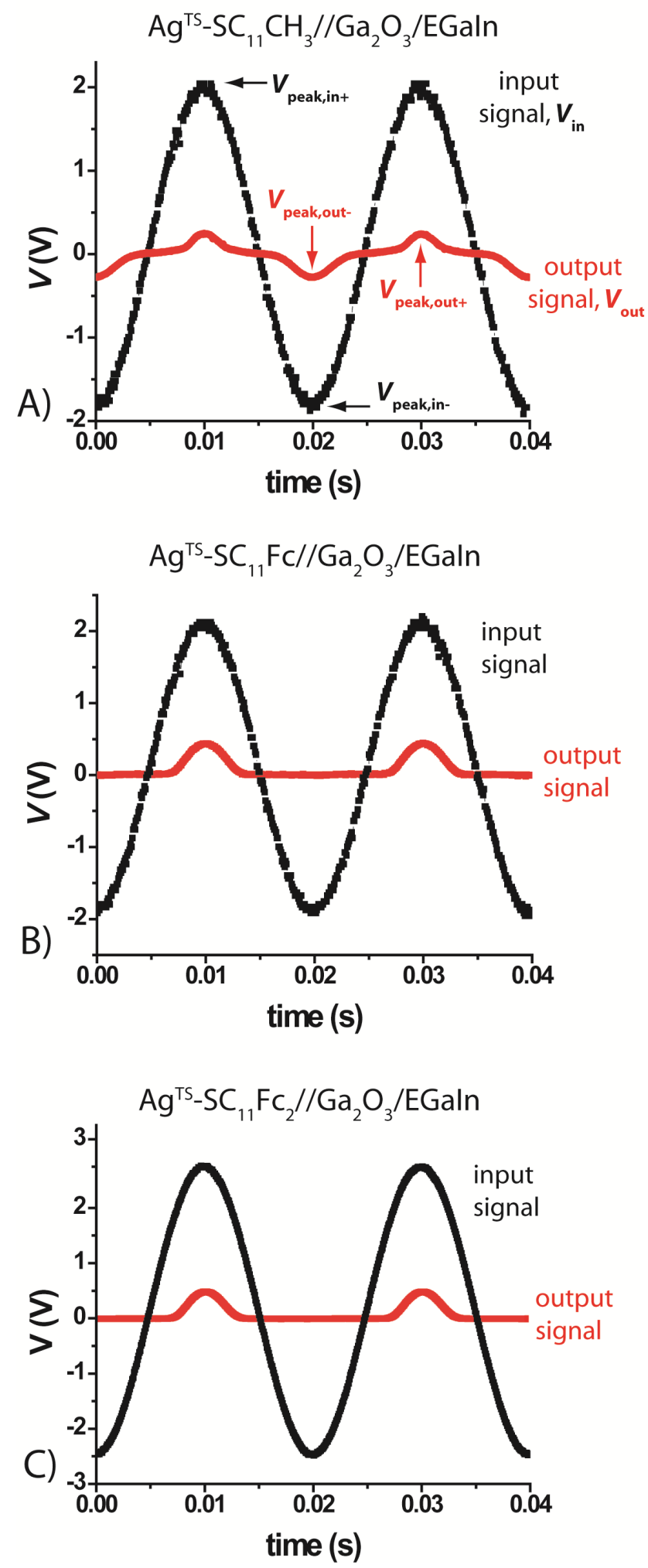
Table 2: Characteristics of the Molecular Junctions.

\begin{tabular}{llllll}
\hline $\mathbf{S A M}$ & $\boldsymbol{R}(\mathbf{D C})^{\mathbf{a}}$ & $\boldsymbol{R}(\mathbf{A C})^{\mathbf{b}}$ & $\boldsymbol{V}_{\text {leak }}(\mathbf{V})^{\mathbf{c}}$ & $\boldsymbol{V}_{\text {break }}(\mathbf{V})^{\mathbf{d}}$ & $\begin{array}{l}\text { Molecular } \\
\text { length }(\mathbf{n m})^{\mathbf{e}}\end{array}$ \\
\hline $\mathrm{SC}_{11} \mathrm{Fc}_{2}$ & $5.0 \times 10^{2}$ & $2.0 \times 10^{2}$ & $2.4 \pm 0.1$ & $-5.0 \pm 0.5$ & 2.8 \\
$\mathrm{SC}_{11} \mathrm{Fc}$ & $1.0 \times 10^{2}$ & $2.0 \times 10^{2}$ & $2.7 \pm 0.1$ & $-4.1 \pm 0.2$ & 2.1 \\
$\mathrm{SC}_{10} \mathrm{CH}_{3}$ & 1.7 & 2 & - & $-1.5 \pm 0.2$ & 1.3 \\
\hline
\end{tabular}

${ }^{a}$ measured at $\pm 1.0 \mathrm{~V}$ using $J(\mathrm{~V})$ curves obtained using DC (Figure 2).

${ }^{\mathrm{b}}$ measured at $\pm 2.0 \mathrm{~V}$ using the data obtained with AC (Figure 5).

${ }^{\mathrm{c}}$ the input voltage at which leakage current is observed

${ }^{\mathrm{d}}$ The effective potential drops across the junctions (see text for details).

e estimated from CPK models. 
The $J(V)$ Characteristics of the Diodes. Solid-state diodes allow current to flow in one direct (at so-called forward bias) while blocking the current in the opposite direction (reverse bias). At forward bias, above a certain threshold voltage (the so-called turn-on voltage: $\sim 0.7 \mathrm{~V}$ for silicon-based $\mathrm{p}$-n diodes), ${ }^{48}$ the current increases exponentionally with voltage. At reverse bias, only a small saturation current is observed until, at very large voltages $(>75 \mathrm{~V})$, avalanche breakdown occurs and current flows. ${ }^{\text {ref }}$ This large current normally leads to irreversible damage to the diode. A certain type of diode - the Zener diode - has a precisely controlled breakdown voltage, the so-called Zener voltage, at which current can flow without causing permanent damage to the diode (permanent damage to these diodes happen at much larger voltages). These diodes are used to control the voltage in a circuit.

To study the behavior of the molecular diodes, we varied the peak voltage of the input signal, $V_{\text {peak,in }}(\mathrm{V})$, and measured the peak voltage of the output signal, $V_{\text {peak,out }}(\mathrm{V})$, across the resistor $(1.5 \mathrm{M} \Omega)$ as a function of time $t$ (see below). Figure 5 shows a plot of $V_{\text {peak,out }}$ as a function of $V_{\text {peak,in. }}$ Fig. 5 shows that the junctions composed of SAMs with $\mathrm{Fc}$ or $\mathrm{Fc}_{2}$ termini have four important characteristics (summarized in Table 2) that we describe in the following sections. i) At low values of $V_{\text {peak,in }}(<0.8 \mathrm{~V}), V_{\text {peak,out }}$ can not be measured with the oscilloscope we used. ii) At values of $V_{\text {peak,in }}$ from $0.80-2.4 \mathrm{~V}$, the diodes rectify. iii) At values of $V_{\text {peak,in }}$ greater than 2.4, the diodes leak current, that is, at negative voltages (or reversed bias), measurable values of $V_{\text {peak,out }}$ are observed. iii) At values of $V_{\text {peak,in }}$ of $5-10 \mathrm{~V}$, the diodes break down, that is, they short.

Figure 5 also shows that the $V_{\text {peak,out }}$ at first increased non-linearly with increasing $V_{\text {peak,in, }}$ but above a certain bias the response became linear. To explain this behavior, we 
discuss the peak voltage drop across the molecular junction $\left(V_{\text {junction }}\right)$. The junction and the resistor lie in series, and since the difference in phase between $V_{\text {in }}$ and $V_{\text {out }}$ is negligible, Kirchoff's circuit laws (eq. 8$)^{49}$ dictate that the sum of the peak voltage drops across the junction and the resistor equals the peak input voltage:

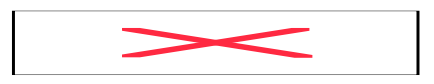

Figure 5 shows that at low values of $V_{\text {peak,in }}$, the values of $V_{\text {peak,out }}$ are small and the values of $V_{\text {junction }}$ approximately equal $V_{\text {peak,in. }}$. This observation implies that the tunneling junctions are more resistive than the $1.5 \mathrm{M} \Omega$ resistor at low bias. Consequently, the tunneling junction dominates the characteristics of the circuit, and gives rise to the nonlinear regime in Fig. 5. Conversely, at high values of $V_{\text {peak,in, }}$, the voltage drop across the resistor meets and exceeds the voltage drop across the tunneling junction. In this regime, the ohmic characteristics of the resistor dominate the plot in Fig. 5. The point of transition between the non-linear and linear regions in Fig. 5 denotes the bias at which the voltage drop (and the resistance) across the tunneling junction is approximately equal to that across the resistor. As expected, the voltage drop across the junctions decreased by replacing the $1.5 \mathrm{M} \Omega$ resistor by a resistor of $15 \mathrm{M} \Omega$, while substituting a $150 \mathrm{k} \Omega$ resistor had the opposite effect and also resulted in shorts at much lower input voltages of $<6.0 \mathrm{~V}$ (see supplemental information) than those junctions in circuits with the two large resistors. 
Figure 5: The $V_{\text {peak,out }}$ as a function of $V_{\text {peak,in }}$ for the $\mathrm{Ag}^{\mathrm{TS}}-\mathrm{SC}_{11} \mathrm{Fc}_{2} / / \mathrm{Ga}_{2} \mathrm{O}_{3} / \mathrm{EGaIn}(\mathrm{A})$, $\mathrm{Ag}^{\mathrm{TS}}-\mathrm{SC}_{11} \mathrm{Fc} / / \mathrm{Ga}_{2} \mathrm{O}_{3} / \mathrm{EGaIn}(\mathrm{B})$, and $\mathrm{Ag}^{\mathrm{TS}}-\mathrm{SC}_{10} \mathrm{CH}_{3} / / \mathrm{Ga}_{2} \mathrm{O}_{3} /$ EGaIn junctions (C). Values of $V_{\text {peak,in }}$ of $<0.8 \mathrm{~V}$ gave values of $V_{\text {peak,out }}$ too small to be measurable with the oscilloscope. The devices rectified in the range $1.0 \mathrm{~V}<V_{\text {peak,in }}<2.4 \mathrm{~V}$. Significant leakages could be observed for $V_{\text {peak,in }}>2.4$ V (See also Fig. 7). See Supplemental Information for an expanded view of Figs. $8 \mathrm{~B}$ and $8 \mathrm{C}$. 

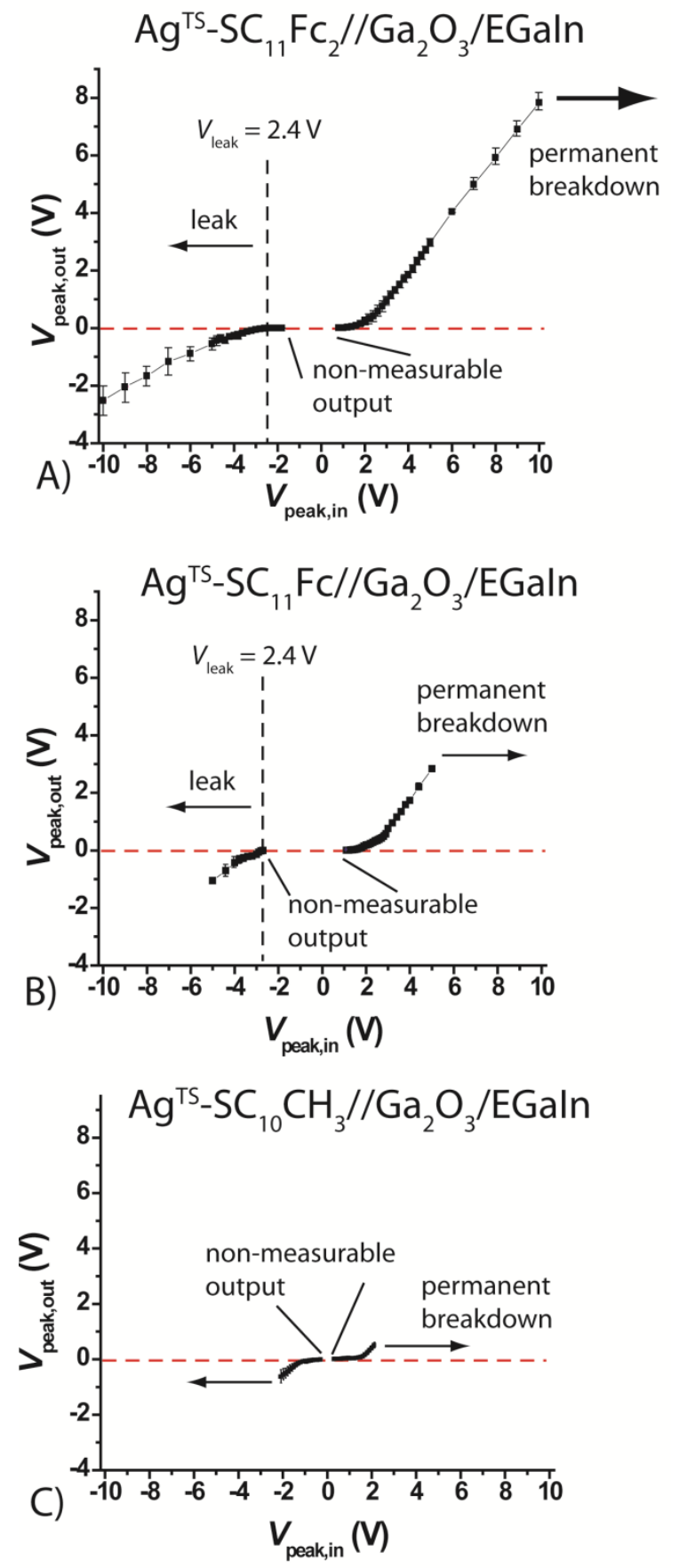
Leak-Voltage. Figure 6 shows $V_{\text {out }}$ (the entire waveform) as a function of time $t$ for three different values of $V_{\text {peak,in }} \leq V_{\text {leak }}$ in circuits incorporating tunneling junctions based on $\mathrm{SAMs}$ of $\mathrm{SC}_{11} \mathrm{Fc}$ and $\mathrm{SC}_{11} \mathrm{Fc}_{2}$, and $\mathrm{SC}_{10} \mathrm{CH}_{3}$.

For junctions having the structure $\mathrm{Ag}^{\mathrm{TS}}-\mathrm{SC}_{11} \mathrm{Fc} / / \mathrm{Ga}_{2} \mathrm{O}_{3} / \mathrm{EGaIn}$ and $\mathrm{Ag}^{\mathrm{TS}}$ $\mathrm{SC}_{11} \mathrm{Fc}_{2} / / \mathrm{Ga}_{2} \mathrm{O}_{3} / \mathrm{EGaIn}$, the oscilloscope detected very small to no output at reverse bias (i.e., low leakage, $|V|<0.005 \mathrm{~V}$ ) for values of $V_{\text {peak,in }}<2.4 \mathrm{~V}$. At $V_{\text {peak,in }} \approx V_{\text {leak }}=2.4 \mathrm{~V}$, the $V_{\text {peak,out }}$ at forward bias for the $\mathrm{Ag}^{\mathrm{TS}}-\mathrm{SC}_{11} \mathrm{Fc} / / \mathrm{Ga}_{2} \mathrm{O}_{3} / \mathrm{EGaIn}$ junctions was $0.31 \pm 0.10$ $\mathrm{V}$ (or $13 \%$ of the value of $V_{\text {peak,in }}$ ) and that of the $\mathrm{Ag}^{\mathrm{TS}}-\mathrm{SC}_{11} \mathrm{Fc}_{2} / / \mathrm{Ga}_{2} \mathrm{O}_{3} / \mathrm{EGaIn}$ junctions was $0.42 \pm 0.18 \mathrm{~V}$ (or $18 \%$ of the value of $V_{\text {peak,in }}$ ). These results imply rectification ratios of $R>100$; this estimate agrees with that obtained with DC measurements (Table 2). Although the junctions composed of $\mathrm{Fc}_{2}$ SAMs perform better than the junctions composed of Fc SAMs, the $V_{\text {peak,out }}$ is less than $\sim 20 \%$ of the $V_{\text {peak,in }}$ when $V_{\text {peak,in }} \approx V_{\text {leak. }}$ Thus, the junctions behave as half-wave rectifiers, but they have large internal resistances.

Figure 7 shows $V_{\text {out }}$ as a function of time $t$ for two different values of $V_{\text {peak,in }}>V_{\text {leak }}$ of circuits composed of tunneling junctions of $\mathrm{SAMs}$ of $\mathrm{SC}_{11} \mathrm{Fc}\left(V_{\text {peak,in }}=3.0\right.$ or $\left.5.0 \mathrm{~V}\right)$, and $\mathrm{SC}_{11} \mathrm{Fc}_{2}\left(V_{\text {peak,in }}=5.0\right.$ or $\left.10.0 \mathrm{~V}\right)$. At values for $V_{\text {peak,in }}>2.4 \mathrm{~V}$ the oscilloscope could measure leakage at reverse bias (Table 2). For $V_{\text {peak,in }} \approx V_{\text {break }}=5.0 \mathrm{~V}$, the value of $V_{\text {peak,out }}=2.84 \pm 0.04 \mathrm{~V}$ for $\mathrm{Ag}^{\mathrm{TS}}-\mathrm{SC}_{11} \mathrm{Fc}_{2} / / \mathrm{Ga}_{2} \mathrm{O}_{3} / \mathrm{EGaIn}$ junction was $57 \%$ of the value of the input signal, but the rectification ratio dropped to 5. For the $\mathrm{Ag}^{\mathrm{TS}}$ -

$\mathrm{SC}_{11} \mathrm{Fc}_{2} / / \mathrm{Ga}_{2} \mathrm{O}_{3} / \mathrm{EGaIn}$ junctions, for $V_{\text {peak,in }}=10.0 \mathrm{~V}$, the value of $V_{\text {peak,out }}=7.8 \pm 0.3 \mathrm{~V}$ was about $78 \%$ of the input signal, but the rectification ratio was only 1.6 (we have not tested this value statistically to determine whether it is distinguishable from $R=1$, or no 
rectification).

Reducing $V_{\text {peak,in }}$ to below the value of $V_{\text {leak }}$ restored half-wave rectification; thus, the processes that let the molecular diode pass current at reverse bias, and eliminate rectification, are reversible, and do not permanently damage these molecular diodes. The sharp decrease in rectification ratio at biases above $2.4 \mathrm{~V}$ and the large decrease of the internal resistance of the tunneling junction clearly imply a change in the mechanisms of charge transport in going from low bias voltage to high bias voltage (see below).

Determination of the Mechanisms of Charge Transport. To investigate the mechanisms of charge transport in the tunneling junctions, we determined the $I(V)$ characteristics of the junction. We report $I(V)$ curves rather than $J(V)$ curves for the AC measurements because we do not know the effective area of the resistor we used in our circuits. Equation 9 describes the voltage across the junction in the circuit summarized in Fig. 1. Kirchoff's circuit laws ${ }^{49}$ further dictate, that since the tunneling junction and the resistor lie in series, and since $V_{\text {in }}$ and $V_{\text {out }}$ are approximately equal in phase, the current flowing through the junction, $I_{\text {junction, }}$ equals the current flowing through the resistor. The latter is given by Ohm's law as voltage divided by resistance (eq. 9).

$$
I_{\text {junction }}=\frac{V_{\text {peak,out }}}{R}
$$

Note that $I_{\text {junction }}$ is the total peak current through the molecular junction, including both tunneling current and possible capacitive current due to the close proximity of the EGaIn and Ag electrodes. Although, the capacitive contribution to current could be determined by frequency-dependent measurements, we have not attempted to 
Figure 6: $V_{\text {out }}$ as a function of time for the $\mathrm{Ag}^{\mathrm{TS}}-\mathrm{SC}_{11} \mathrm{Fc}_{2} / / \mathrm{Ga}_{2} \mathrm{O}_{3} / \mathrm{EGaIn}(\mathrm{A}-\mathrm{C}), \mathrm{Ag}^{\mathrm{TS}}-$ $\mathrm{SC}_{11} \mathrm{Fc} / / \mathrm{Ga}_{2} \mathrm{O}_{3} / \mathrm{EGaIn}(\mathrm{D}-\mathrm{F})$, and $\mathrm{Ag}^{\mathrm{TS}}-\mathrm{SC}_{10} \mathrm{CH}_{3} / / \mathrm{Ga}_{2} \mathrm{O}_{3} / \mathrm{EGaIn}$ (G-I) junctions with three different $V_{\text {in }}$. The red dashed line indicates $V_{\text {out }}=0.0 \mathrm{~V}$ 

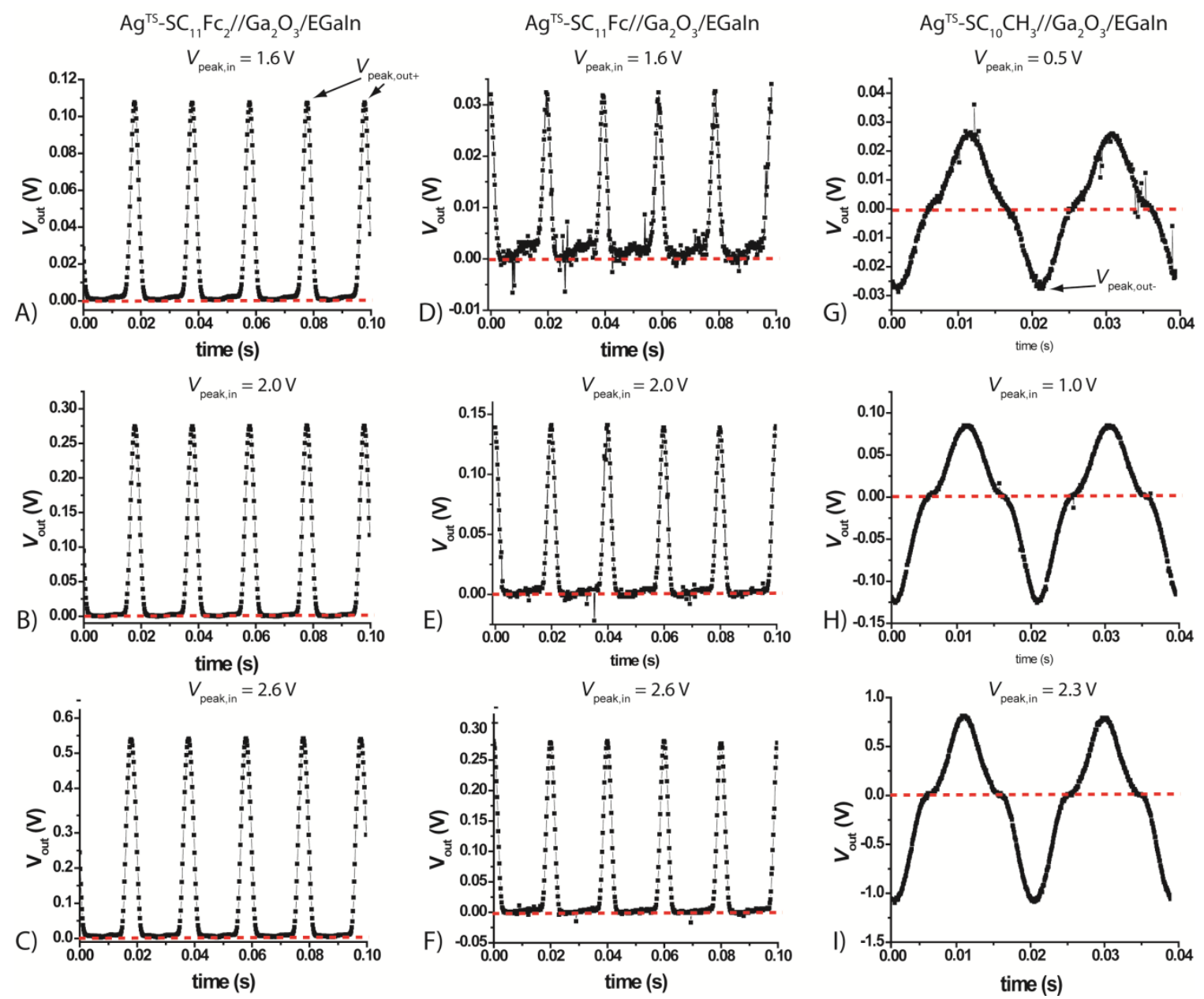
Figure 7: $V_{\text {out }}$ as a function of time using a sinusoidal input signal with an amplitude of $5.0 \mathrm{~V}(\mathrm{~A})$ and $10.0 \mathrm{~V}(\mathrm{~B})$ for the $\mathrm{Ag}^{\mathrm{TS}}-\mathrm{SC}_{11} \mathrm{Fc}_{2} / / \mathrm{Ga}_{2} \mathrm{O}_{3} / \mathrm{EGaIn}$ junctions, and $3.0 \mathrm{~V}(\mathrm{C})$ and $5.0 \mathrm{~V}$ (D) for the $\mathrm{Ag}^{\mathrm{TS}}-\mathrm{SC}_{11} \mathrm{Fc} / / \mathrm{Ga}_{2} \mathrm{O}_{3} / \mathrm{EGaIn}$ junctions. 

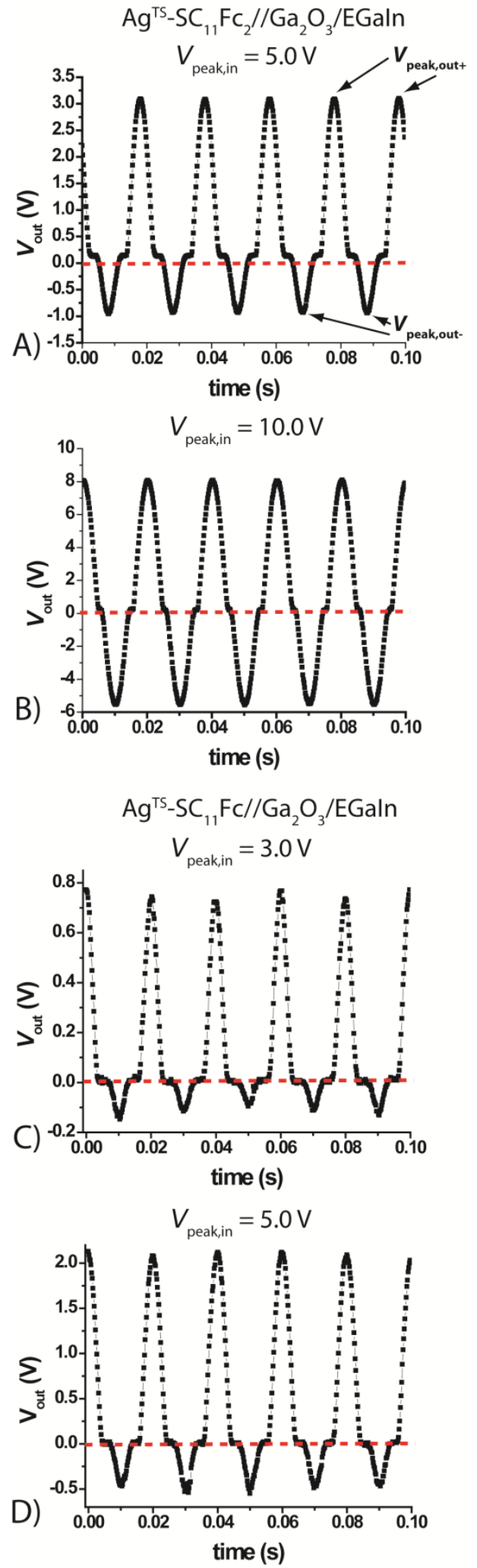
separate these two contributions due to the limitations of our simple apparatus at high frequencies. Instead, we used a frequency of $50 \mathrm{~Hz}$ and assumed that at this low frequency any capacitive contributions were not important.

To construct $I(\mathrm{~V})$-curves for the junctions, we determination $I_{\text {junction }}$ and $V_{\text {junction }}$ with eq. 8 and eq. 9. Figure $8 \mathrm{~A}$ shows the $I(\mathrm{~V})$ curve obtained for the $\mathrm{Ag}^{\mathrm{TS}}$ $\mathrm{SC}_{11} \mathrm{Fc}_{2} / / \mathrm{Ga}_{2} \mathrm{O}_{3} / \mathrm{EGaIn}$ junctions over the range $-4.0<V_{\text {junction }}<2.0 \mathrm{~V} . V_{\text {junction }}$ did not exceed these limits, even at extreme values of $V_{\text {peak,in }}( \pm 10 \mathrm{~V})$, because, at these values of $V_{\text {junction, }}$ the SAM is relatively conductive, and any increase in $V_{\text {peak,in }}$ manifests as an increased potential drop across the resistor, rather than the SAM. While $V_{\text {junction }}$ remains roughly constant at large values of $V_{\text {peak,in }}, I_{\text {junction }}$ still increases linearly with increasing input voltage. The $I(V)$ curve of the molecular diode near the extreme values of $V_{\text {junction }}=$ $-4.0 \mathrm{~V}$ and $2.0 \mathrm{~V}$ is, therefore, unreliable and has a large error. The region of the $I(V)$ curve between $-1.7 \mathrm{~V}<V_{\text {junction }}<0.7 \mathrm{~V}$ was not accurately measurable due to the insensitivity of the oscilloscope. Figure 3, however, shows the $J(\mathrm{~V})$ curve for the bias range of $\pm 1.0 \mathrm{~V}$ obtained by DC experiments. Thus, Figs $8 \mathrm{~A}$ and $3 \mathrm{~A}$ show the electrical characteristics over the entire bias regime from -4.0 to $2.0 \mathrm{~V}$.

Figure $8 \mathrm{~B}$ shows a plot of $\ln \left(I / V^{2}\right)$ vs. $1 / V$, i.e., a Fowler-Nordheim plot, of the same data shown in Fig. 8A for $\mathrm{Ag}^{\mathrm{TS}}-\mathrm{SC}_{11} \mathrm{Fc}_{2} / / \mathrm{Ga}_{2} \mathrm{O}_{3} / \mathrm{EGaIn}$ junctions at positive bias. Figure $8 \mathrm{C}$ shows the Fowler-Nordheim plot for the data obtained in DC experiments (Figure 3A). These plots show three characteristics. The Fowler-Nordheim plots (Figs. $8 \mathrm{~B}$ and $8 \mathrm{C}$ ) show i) a clear transition from logarithmic growth to linear decay 
Figure 8: A) Plot of current through the SAM ( $\left.I_{\text {junction}}\right)$ vs. voltage across the SAM ( $V_{\text {junction}}$ ) averaged over six junctions of $\mathrm{Ag}^{\mathrm{TS}}-\mathrm{SC}_{11} \mathrm{Fc}_{2} / / \mathrm{Ga}_{2} \mathrm{O}_{3} / \mathrm{EGaIn}$. The text describes the procedure for calculating $I_{\text {junction }}$ and $V_{\text {junction. }}$ B) A plot of $\ln \left(\left|I / V_{\text {junction }}{ }^{2}\right|\right)$ vs. $1 / V_{\text {junction }}$ for the $\mathrm{Ag}^{\mathrm{TS}}-\mathrm{SC}_{11} \mathrm{Fc}_{2} / / \mathrm{Ga}_{2} \mathrm{O}_{3} / \mathrm{EGaIn}$ junction at positive bias. The solid black line is a least-squares fits to eq. $\mathbf{6}$ and indicates the region with FowlerNordheim tunneling as the dominant mechanism of charge transport. The dashed black line is a guide to the eyes and indicates the region with hopping as the dominant mechanism of charge transport. C) A plot of $\ln \left(\left|I / V_{\text {junction }}{ }^{2}\right|\right)$ vs. $1 / V_{\text {junction }}$ for the $\mathrm{Ag}^{\mathrm{TS}}-\mathrm{SC}_{11} \mathrm{Fc}_{2} / / \mathrm{Ga}_{2} \mathrm{O}_{3} / \mathrm{EGaIn}$ junction for junctions of $\mathrm{Ag}^{\mathrm{TS}}-\mathrm{SC}_{11} \mathrm{Fc}_{2} / / \mathrm{Ga}_{2} \mathrm{O}_{3} / \mathrm{EGaIn}$, using the data obtained by DC methods (Fig. 3). The dashed line indicates $V_{\text {trans,TH }}=$ $0.50 \mathrm{~V}$, the transition from tunneling to hopping. 

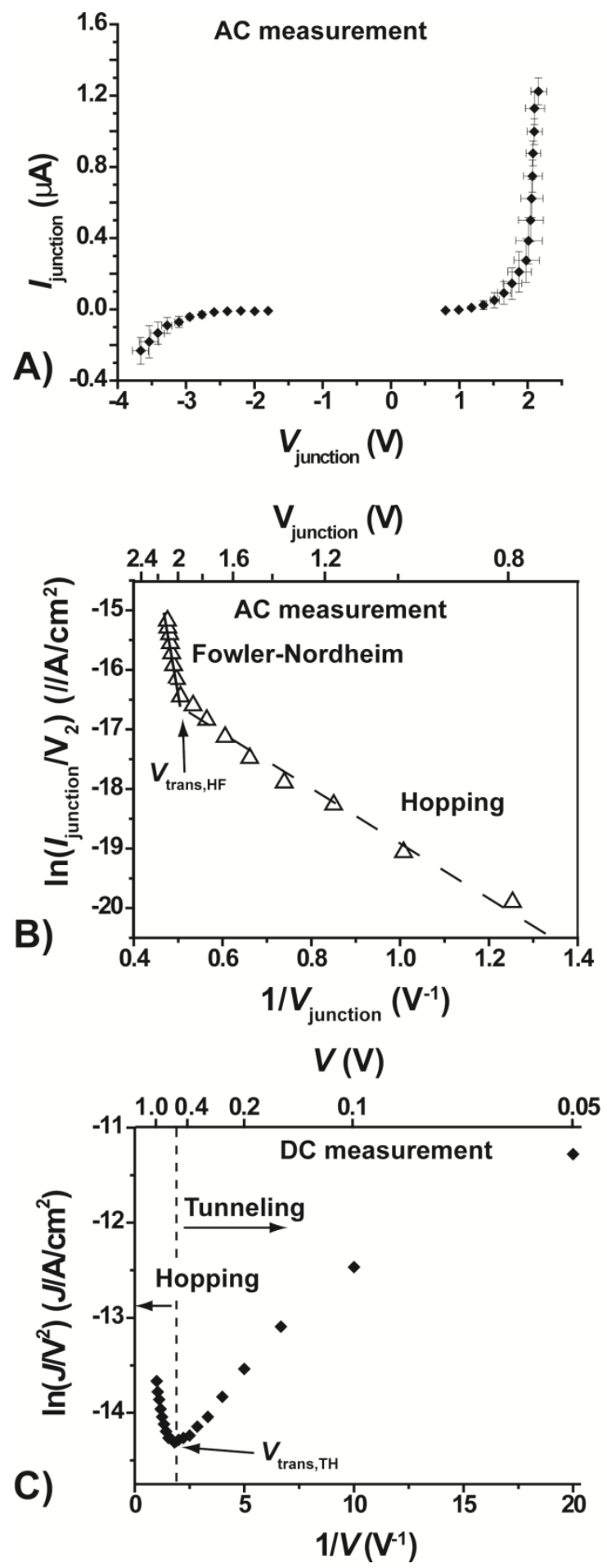
(Fig. 8C), ii) a cusp (i.e., a point where the tangent to the curve abruptly changes slope) in the region of logarithmic growth (Fig. 8B), and iii) that this cusp is only observed at positive bias, and not at negative bias.

We first discuss the mechanisms of charge transport at positive bias. At low bias of $<0.50 \mathrm{~V}$ the Fowler-Nordheim plot indicates that tunneling is the dominant mechanism of charge transport. In this regime of voltage, $J(\mathrm{~V})$ measurements as a function of temperature indicate that indeed tunneling is the dominant mechanism of charge transport. ${ }^{31}$ At voltages in the range over $0.50-1.9 \mathrm{~V}$, the Fowler-Nordheim plot shows a linear increase, and the slope of this line changes at $1.9 \mathrm{~V}$ resulting in a cusp (Table 3 ). We showed that for junctions of $\mathrm{Ag}^{\mathrm{TS}}-\mathrm{SC}_{11} \mathrm{Fc} / / \mathrm{Ga}_{2} \mathrm{O}_{3} / \mathrm{EGaIn}$ (by $J(\mathrm{~V})$ measurements as a function of temperature using DC methods) that hopping is the dominant mechanism of charge transport in the bias range of $0.50-1.0 \mathrm{~V} .{ }^{31} \mathrm{We}$ did not observe hopping at opposite bias. For this bias range, Fowler-Nordheim tunneling, which has negligible temperature dependence, is excluded as a possible mechanism. We believe that the mechanism of charge transport changes from tunneling to hopping at $V=0.50 \mathrm{~V}$ and call this transition "the transition voltage from tunneling to hopping", or $V_{\text {trans,TH. We believe }}$ that the increase in the slope in the Fowler-Nordheim plot (Fig. 8C) at $V=1.9 \mathrm{~V}$ indicates a transition in the mechanism of charge transport from hopping to Fowler-Nordheim tunneling and we call this transistion "the transition voltage from hopping to Fowler-

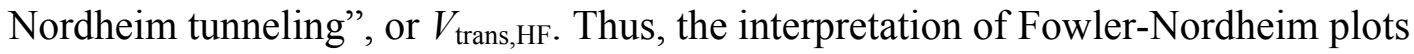
needs to be careful because the minimum in the Fowler-Nordheim plots do not necessary 
indicate a change in the mechanism of charge transport form tunneling to FowlerNordheim tunneling.

The mechanism of charge transport at positive bias is different from that at negative bias. The Fowler-Nordheim plot for negative bias also shows a transition in the mechanism of charge transport. We believe that this transition indicates a change in the mechanism of charge transport from tunneling (at biases less than $-0.50 \mathrm{~V}$ ) to FowlerNordheim tunneling (at biases greater than $-0.50 \mathrm{~V}$ ). The Fowler-Nordheim plot obtained for large negative bias obtained with the AC experiments does not show a change in the slope of the graph, or cusp. Thus, the mechanism of charge transport is consistent with Fowler-Nordheim tunneling over the entire bias regime of -0.50 to $-4.0 \mathrm{~V}$.

Our findings agree with our earlier finding that the rectification by the SAMs with Fc termini is caused by the fact that hopping is the dominant mechanism of charge transport in one direction of bias, and not in the other (Fig. 2) ${ }^{31}$ But here we show that at voltages larger than $V_{\text {trans,HF}}$, Nordheim-Fowler tunneling is the dominant mechanism of charge transport in both directions of bias and causes rectification to diminish to a value close to unity (see below). Junctions with $\mathrm{SAMs}$ of $\mathrm{SC}_{11} \mathrm{Fc}$ and $\mathrm{SC}_{11} \mathrm{Fc}_{2}$ behave in the same way, but with slightly different values of $V_{\text {trans,HF }}$ (Table 3 ). Tables 2 and 3 show

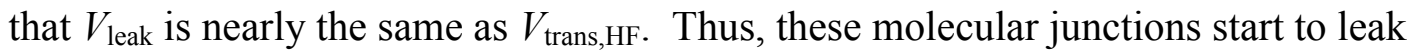
current shortly after the mechanism of charge transport changes from hopping to FowlerNordheim tunneling.

Figure 9 shows the three energy level diagrams of the junctions of $\mathrm{Ag}^{\mathrm{TS}}$ $\mathrm{SC}_{11} \mathrm{Fc}_{2} / / \mathrm{Ga}_{2} \mathrm{O}_{3} / \mathrm{EGaIn}$ for open circuit, and at applied biases $V=-1.0 .-2.4$, or $-3.4 \mathrm{~V}$ and summarizes the mechanisms of charge transport across these junctions in the three 
different potential ranges of $0 \mathrm{~V}<V_{\text {trans,TH, }} V_{\text {trans,TH }}<V<V_{\text {trans,HF }}$ and $V>V_{\text {trans,HF. The }}$ potentials drops across these junctions have been described in reference 3 and are briefly described in the Background Section. At a biases of magnitude less than $0.5 \mathrm{~V}$, or lower than $V_{\text {trans, } \mathrm{TH}}$, these measurements indicated that tunneling across the whole SAMs is the dominant mechanism of charge transport and the molecular diodes do not rectify $(R \approx 1$ 5). At a bias of $V_{\text {trans,TH }}<|V|<V_{\text {trans,HF}}$, the dominant mechanism of charge transport is hopping in only direction of bias (here negative) and not the other and the molecular diodes have their maximal rectification ratios $(R>100),{ }^{3,31}$ At biases of $|V|>V_{\text {trans,HF, }}$ Fowler-Nordheim tunneling is the dominant mechanism of charge transport and the molecular diodes do not rectify $(R \approx 1-5)$.

Breakdown Voltage. To test the robustness of the molecular diodes, we increased $V_{\text {peak,in }}$ until the output signal changed irreversibly. Irreversible breakdown indicated a short across the molecular junction, and resulted in $V_{\text {in }}=V_{\text {out }}$ (the same result observed for an $\mathrm{Ga}_{2} \mathrm{O}_{3} / \mathrm{EGaIn}$-tip contacting a bare $\mathrm{Ag}^{\mathrm{TS}}$ substrate lacking a SAM).

In DC experiments, ${ }^{1,3}$ the voltage of breakdown for the $\mathrm{Ag}^{\mathrm{TS}}-\mathrm{SC}_{11} \mathrm{Fc}_{2} / / \mathrm{Ga}_{2} \mathrm{O}_{3} / \mathrm{EGaIn}$ junctions was approximately $1.5 \mathrm{~V}$. In these experiments, the voltage dropped almost entirely across the junction because a resistor in series to the junction is not present.

In our $\mathrm{AC}$ experiments (Fig. 1), the voltage of breakdown in our tunneling junctions was much higher (Table 2). We report the voltage of breakdown in terms of the actual voltage drop across the junction at negative bias, not the input voltage $\left(V_{\text {peak,in }}\right)$, which drops across both the junction and the resistor. At large values of $V_{\text {peak,in, }}$, the junctions were damaged permanently and the circuits shorted; the corresponding peak voltage 
Figure 9: Schematic representations of the proposed energy level diagrams for $\mathrm{Ag}^{\mathrm{TS}}$ $\mathrm{SC}_{11} \mathrm{Fc}_{2} / / \mathrm{Ga}_{2} \mathrm{O}_{3} / \mathrm{EGaIn}$ junctions for the applied voltages $V$ in the range of $0<\mathrm{V}<$ $V_{\text {trans,TH }}$ when tunneling dominates $\left(V=0.2 \mathrm{~V}\right.$; left), $V$ in the range of $V_{\text {trans,TH }}<V<$ $V_{\text {trans,HF }}$ when hopping dominates $\left(V=1.0 \mathrm{~V}\right.$; middle), and $V$ in the range of $\mathrm{V}>V_{\text {trans,HF }}$ $(V=2.5 \mathrm{~V}$; right $)$ when Fowler-Nordheim tunneling dominates the mechanism of charge transport. 


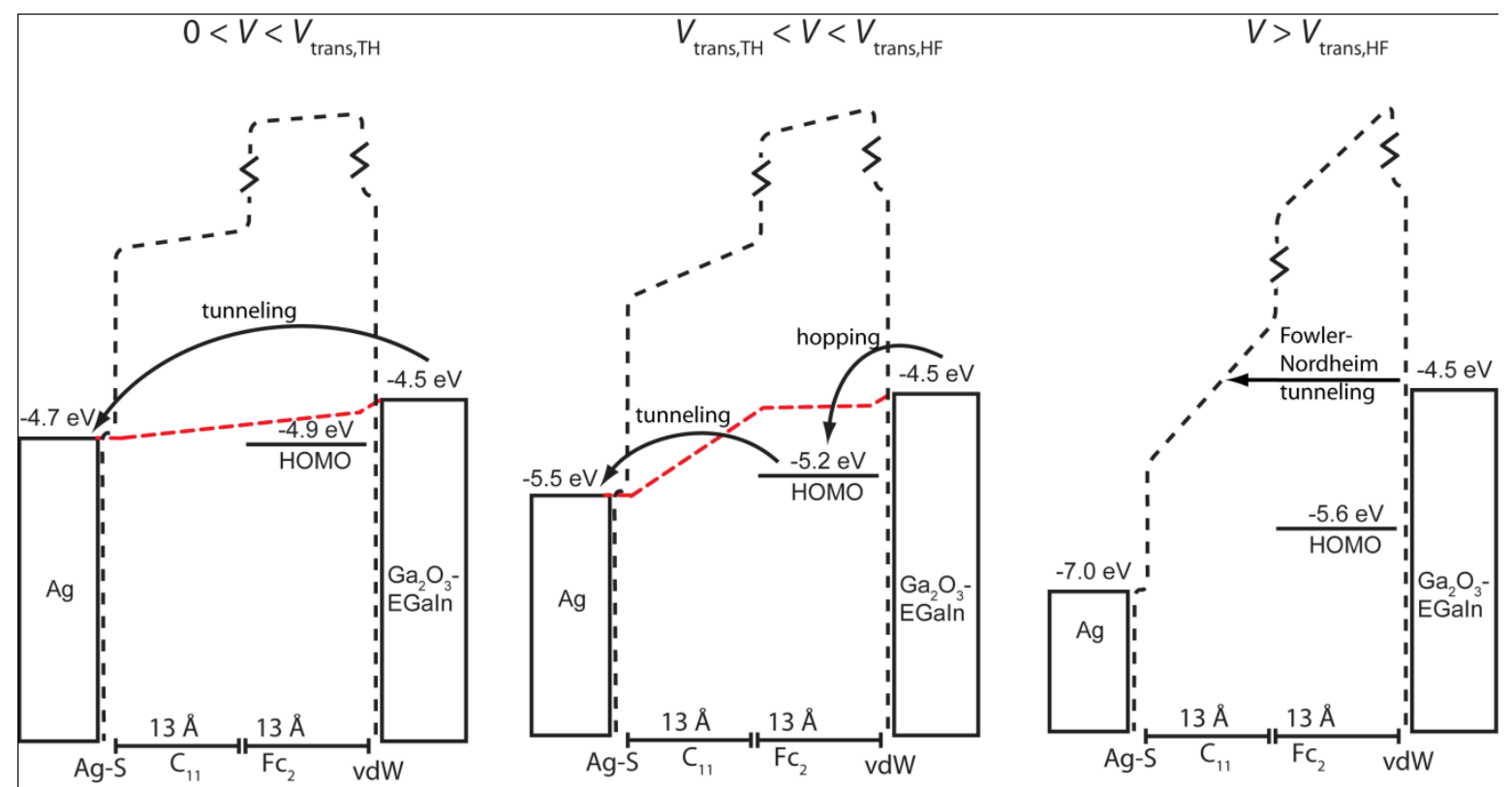


Table 3: The Different Types of Transition Voltages for the junctions of $\mathrm{Ag}^{\mathrm{TS}}$ $\mathrm{SAM} / / \mathrm{Ga}_{2} \mathrm{O}_{3} / \mathrm{EGaIn}$ junctions.

\begin{tabular}{lll}
\hline $\mathbf{S A M}$ & $\boldsymbol{V}_{\text {trans,TH }}(\mathbf{V})^{\mathbf{a}}$ & $\boldsymbol{V}_{\text {trans, } \mathbf{H F}}(\mathbf{V})^{\mathbf{c}}$ \\
\hline $\mathrm{SC}_{10} \mathrm{CH}_{3}$ & - & 1.3 \\
$\mathrm{SC}_{11} \mathrm{Fc}^{\mathrm{b}}$ & 0.50 & 2.1 \\
$\mathrm{SC}_{11} \mathrm{Fc}_{2}$ & 0.50 & 1.9 \\
\hline
\end{tabular}

${ }^{\mathrm{a}} V_{\text {trans,TH }}$ is the transition voltage at which we observed the transition in the mechanism of charge transport from tunneling to hopping.

${ }^{\mathrm{b}}$ Temperature dependent measurements indicated that hopping does not occur across these SAMs

${ }^{\mathrm{c}} V_{\text {trans,HF }}$ is the transition voltage at which we observed the transition in the mechanism of charge transport from hopping to Fowler-Nordheim tunneling. 
across the junction was greater for negative bias than for positive bias. Since the positive peak voltage across the rectifying junctions was roughly independent of $V_{\text {peak,in }}$ at large bias, we suspect that irreversible breakdown occurs under negative applied bias. We therefore define the irreversible breakdown voltage as the peak negative voltage across the junction when breakdown occurs (Table 2). Figure 10 shows the irreversible breakdown voltage as a function of the thickness of the monolayer $d$. The electric field $E$ between two parallel plates depends on the applied voltage $V$ and the distance $d$ between the two plates (eq. 10).

$$
E=V / d
$$

Here, we assume the distance between the two electrodes to be defined by the thickness of the SAM (that is, we neglect other contributions to contact resistance). According to eq. 10, for a given applied voltage, thicker SAMs experience weaker electric fields between electrodes than do thinner SAMs, and are, therefore, less prone to breakdown. ${ }^{50}$ The slope of the linear fit of the plot in Figure 9 approximates the field required to achieve breakdown in these junctions as $1.8 \pm 0.2 \times 10^{9} \mathrm{~V} / \mathrm{m}$. Following eq. 10, the linear fit was artificially constrained to pass through the origin.

Our experiment indicates that the thickness of the SAM primarily determines the breakdown voltage: the thicker the SAM the higher the value of the breakdown voltage. These findings are in agreement with a much more comprehensive study concerning the breakdown voltage down involving a large number of SAMs of different chemical structures. ${ }^{50}$ This study concluded that the breakdown voltage is $\sim 0.8 \times 10^{9} \mathrm{~V} / \mathrm{m}$, is insensitive to the chemical structure of the SAM, and is primarily determined by the thickness of the SAM inside the junction. ${ }^{50}$ The value for the breakdown voltage we 
Figure 10: The linear dependence of the irreversible breakdown voltage on the thickness of the $\mathrm{SAMs}\left(\mathrm{SC}_{11}, \mathrm{SC}_{11} \mathrm{Fc}\right.$, and $\mathrm{SC}_{11} \mathrm{Fc}_{2}$, from left to right. Breakdown occurred at negative bias for all SAMs. The dotted line shows a linear fit, constrained to pass through the origin, of the three points. The slope of this fit represents the approximate field required to achieve breakdown. The error bars represent the standard deviation of six measurements. 


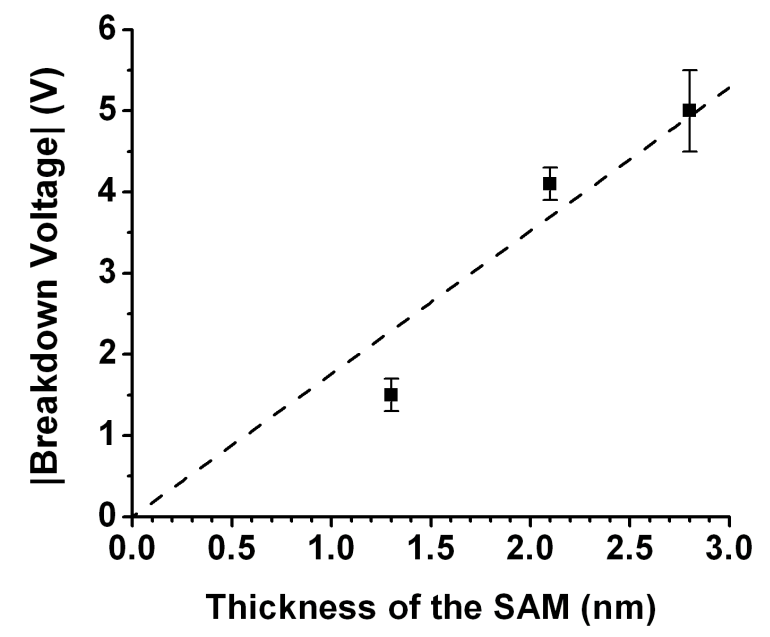


determined using AC methods is about a factor of two larger than the value reported obtained by DC methods. ${ }^{50} \mathrm{We}$ believe that this difference in breakdown voltages indicates that using an AC signal does, indeed, minimize the formation of, for instance, metal filaments inside the junctions. ${ }^{29,28}$

\section{Rectification ratio determined by half-wave rectification. Normally, we} determine the value of $R$ by DC measurements using eq. 1. The rectification ratio can also be determined when the molecular diodes are operating as half-wave rectifiers. In this type of experiment, the ratio of the peak potential at positive bias ( $\left.V_{\text {peak,out }+}\right)$ to the peak potential at negative bias ( $\left.V_{\text {peak,out- }}\right)$ at the output gives the rectification ratio as described by eq. 11 .

$$
R=V_{\text {peak,out }+} / V_{\text {peak,out- }}
$$

Figure 6 shows the output characteristics of the diodes. Thus, at biases greater than $V_{\text {leak }}$, the rectification ratio can be determined by simply dividing the peak positive potential of the output signal by the peak negative potential. At biases less than $V_{\text {leak }}$, the output signals are too small to be detectable by the simple oscilloscope we used in this study, and $R$ could not be determined reliably using this method. We determined the values of $R$ reliably using DC experiments; Fig. 3 shows that the rectification ratios at a bias of $\pm 1 \mathrm{~V}$ are $>10^{2}$. Figure S2 shows the $J(\mathrm{~V})$ curves obtained with DC measurement for a $\mathrm{Ag}^{\mathrm{TS}}-\mathrm{SC}_{11} \mathrm{Fc}_{2} / / \mathrm{Ga}_{2} \mathrm{O}_{3} / \mathrm{EGaIn}$ junction measured at potentials up to $2.0 \mathrm{~V}(<5 \%$ of the junctions withstood this bias range, none of the $\mathrm{Ag}^{\mathrm{TS}}-\mathrm{SC}_{11} \mathrm{Fc} / / \mathrm{Ga}_{2} \mathrm{O}_{3} / \mathrm{EGaIn}$ could withstand potentials larger than $\pm 1.5 \mathrm{~V}$ ). Figure $\mathrm{S} 2$ shows that this junction rectified 
maximally up to $2.0 \mathrm{~V}\left(R \approx 1.0 \times 10^{3}-1.2 \times 10^{3}\right.$ measured at $\left.\pm 2.0 \mathrm{~V}\right)$, indicating consistency between $\mathrm{AC}$ and $\mathrm{DC}$ measurements with respect to rectification.

The rectification ratio is not constant and depends on the $V_{\text {peak,in }}$ (Figs. 6-8). Figure 11 shows the $R$ of the $\mathrm{Ag}^{\mathrm{TS}}-\mathrm{SC}_{11} \mathrm{Fc}_{2} / / \mathrm{Ga}_{2} \mathrm{O}_{3} / \mathrm{EGaIn}$ junctions as a function $V_{\text {peak,in. }}$. Figure 11 shows that, at biases less than $V_{\text {leak }}, R$ cannot be determined reliably using eq. 11. The tunneling junctions still rectified in this bias regime, even though $R$ could not be quantified. Hopping, at negative bias, and field emission, at positive bias, dominate the mechanism of charge transport. At biases greater than $V_{\text {leak }}$, Figure 11 shows that $R$ drops close to unity. Thus, as concluded earlier, in this bias regime the tunneling junctions are not rectifying, and the mechanism of charge transport is dominated by field emission in both directions of bias. 
Figure 11: The rectification ratio of the $\mathrm{Ag}^{\mathrm{TS}}-\mathrm{SC}_{11} \mathrm{Fc}_{2} / / \mathrm{Ga}_{2} \mathrm{O}_{3} / \mathrm{EGaIn}$ junctions determined as the ratio of $V_{\text {peak,out }}$ and $V_{\text {peak,out- }}$ as a function of $V_{\text {peak,in. }}$ 


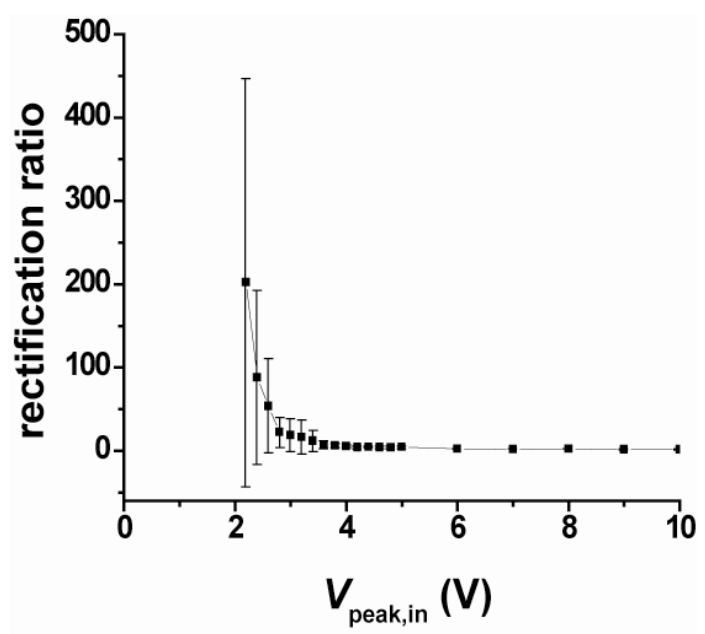




\section{Conclusions}

Molecular Diodes can Operate as Half-Wave Rectifiers. The method described in this paper to study the mechanism of charge transport across SAM-based junctions makes it possible to study the performance of molecular diodes in real circuitry - here circuits in which they replaced a conventional diode - and only requires a wave generator and an oscilloscope. We used AC signals of $50 \mathrm{~Hz}$ with amplitudes ranging from $0.8-$ 10.0 $\mathrm{V}$ and showed that these molecular diodes can operate as half-wave rectifiers. The properties of these molecular diodes of the form $\mathrm{Ag}^{\mathrm{TS}}-\mathrm{SC}_{11} \mathrm{Fc}_{\mathrm{m}} / / \mathrm{Ga}_{2} \mathrm{O}_{3} / \mathrm{EGaIn}(\mathrm{m}=1$ or 2) are different from that of classic diodes. These molecular diodes behave as half-wave rectifiers up to a voltage across the junction of $\sim 1.9 \mathrm{~V}$, above which the rectification ratio decreases almost to unity, i.e., no rectification. Lowering the voltage to below this value restored rectification. At voltages of $5.0 \mathrm{~V}$, or higher for the thickest SAM in this study of $\mathrm{SC}_{11} \mathrm{Fc}_{2}$, the molecular diodes tend to breakdown by shorting. These molecular diodes rectified for 30-40 min with sinusoidal signals (with an amplitude of $2.0-3.0 \mathrm{~V}, 50 \mathrm{~Hz}$ ), that is $>10^{5}$ cycles.

\section{The Breakdown Voltage in AC experiments is Larger than in DC}

Experiments. The breakdown voltage of the junctions of $1.8 \pm 0.2 \mathrm{GV} / \mathrm{m}$ determined by this AC method is about a factor of two larger than that determined by DC methods. ${ }^{50}$ This difference in breakdown voltage might indicate that during AC measurements the formations of metal filaments, and possibly other processes leading to failure, are minimized. These processes are slower than the time scale of the experiment (20 ms at a frequency of $50 \mathrm{~Hz}$ ), at least, and perhaps to some extend, reversible. ${ }^{29,28}$ Thus, using this 
AC method makes it possible to study charge transfer processes across SAM-based junctions over a much wider potential range than using DC methods.

The Mechanism of Charge Transport Changes a Function of Applied Bias and Involves Tunneling, Hopping, and Fowler-Nordheim Tunneling. Using this method, we indentified three different types of charge transport. i) At biases across the junctions in the range of 0 to $0.5 \mathrm{~V}$, tunneling dominates the mechanism of charge transport and the molecular diodes do not rectify $(R \approx 1-5)$. ii) At biases in the range of 0.5 to $2.4 \mathrm{~V}$, hopping dominates the mechanism of charge transport in one direction of bias, and tunneling in the other, and the molecular diodes have their maximum rectification ratios $(R>100)$. iii) At biases above $2.4 \mathrm{~V}$ till the breakdown voltage, Fowler-Nordheim tunneling dominates the mechanism of charge transport and the molecular diodes do not rectify $(R \approx 1-5)$.

\section{The Interpretation of Fowler-Nordheim Plots without Temperature-}

Dependent Data Might be Ambiguous. In large electric fields ( $\mathrm{GV} / \mathrm{m})$, the mechanism of charge transport can change from tunneling to Fowler-Nordheim tunneling, that is, electron emission from the metal electrodes to the SAM under the influence of large electric fields. Normally, plotting $J(\mathrm{~V})$ data in so-called Fowler-Nordheim plots (Fig. 8) show if a transition in the mechanism of charge transport from tunneling to FowlerNordheim tunneling occurs if a transition voltage $V_{\text {trans }}-$ the voltage at which a minimum is observed in Fowler-Nordheim plots - is observed. We showed that the interpretation of $J(\mathrm{~V})$ data plotted in so-called Fowler-Nordheim plots needs to be careful: the observation of $V_{\text {trans }}$ does not necessary mean that the mechanism of charge transport changes from tunneling to field emission, or so-called Fowler-Nordheim tunneling (Fig. 8). We 
observed a minimum in these plots (at $V=0.50 \mathrm{~V}$; Fig. $8 \mathrm{C}$ ), but temperature dependent measurements ruled out the transition from tunneling to field emission (both are independent of temperature) at this bias, but indicated a transition from tunneling to hopping (which is dependent on the temperature). We observed a change in the mechanism of charge transport from hopping to Fowler-Nordheim tunneling that resulted in a cusp in the Fowler-Nordheim plot at $V \approx 1.9 \mathrm{~V}$ (Fig. 8B). Without temperature dependent measurements, thus, interpretation of Fowler-Nordheim plots might be ambiguous because the observation of $V_{\text {trans }}$ might indicate the transition of tunneling to hopping rather than the transition from tunneling to Fowler-Nordheim tunneling.

\section{Our Molecular Diodes Do Not Meet the Standards of Commercial Diodes.}

Normally molecular diodes are only discussed in terms of rectification ratios determined in DC experiments: molecular diodes with high values of $R$ are better than those with low values of $R$. The terms high and low are not well-defined, but values of $R>10$ are considered to be high in most studies of organic rectifiers, ${ }^{6,10,13,51}$ but many studies report values of $R<10$ (and, in fact, as "rectifying" values close to one, we regard these values as non statistically different from one, and believe that without statistical validation they can not be considered to be rectifying). ${ }^{7,9,16,17}$ Commercially available conventional diodes, however, fulfill many specifications depending on the specific applications. ${ }^{48}$ Here we indentify four characteristics that are important to all types of diodes. i) The rectification ratio has to be large ( $R$ increases exponentially from a turn-on voltage and can reach values of $10^{4}-10^{8}$ ). ii) The internal resistance at forward bias must be low (typically $<10 \Omega$ at the turn-on voltage, and even lower at higher bias), while the current at reverse bias (saturation current) must also be minimal (typically $<10^{-5} \mathrm{~A}$ ). iii) The 
lifetime must be long (years). iv) The operational bias window, outside of which the diode breaks down, must be large $(|V|>50-70 \mathrm{~V}$, although for specific applications smaller bias windows are acceptable).

Our molecular diodes do not fulfill any of these four requirements. i) The rectification ratios are too low, although the values we report for our molecular rectifier are the largest reported to date for an interpretable, statistically validated SAM-based system. ii) The resistance in forward bias is too large (in the order of $10^{6} \Omega$ ) when operating under conditions with the largest values of $R(\geq 100)$. iii) The life times are too short (30-40 min in operation). iv) The bias window (maximum value of $\pm 5 \mathrm{~V}$ for junctions of $\left.\mathrm{Ag}^{\mathrm{TS}}-\mathrm{SC}_{11} \mathrm{Fc}_{2} / / \mathrm{Ga}_{2} \mathrm{O}_{3} / \mathrm{EGaIn}\right)$ at which the diodes can operate is too small. Thus, to indentify "good" molecular diodes only by comparison of the rectification ratios with other organic thin films is not sufficient to conclude or imply that these molecular diodes have any potential for practical use as rectifiers.

Inherent Limitations of Molecular Diodes. We identified two inherent limitations of our molecular diodes, which may apply to any other molecular diode. i) The molecular diodes change the mechanism of charge transport from hopping (in one direction of bias) and tunneling (in the other direction of bias) to Fowler-Nordheim tunneling (in both directions of bias) for values of $V_{\mathrm{in}}>V_{\mathrm{TF}} \approx 2.4 \mathrm{~V}$ at which the values of $R$ decreased to values of close to unity, i.e., no rectification. In this bias regime the mechanism of charge transport is not determined by the chemical structure of the SAMs. Thus, the performances of molecular diodes are limited by the transition from any type of charge transport to Fowler-Nordheim tunneling at large input biases. ii) The molecular diodes breakdown (probably by shorting) in a field of $1.8 \mathrm{GV} / \mathrm{m}$; this field seems to be 
independent of the chemical structure of the SAM. Thus, molecular diodes of even the size of large $(5 \mathrm{~nm})$ molecules will breakdown at an input voltage exceeding $\sim 10 \mathrm{~V}$ (or 2 $\mathrm{GV} / \mathrm{m})$.

\section{Acknowledgements}

C.A.N. acknowledges the Netherlands Organization for Scientific Research (NWO) for the Rubicon grant supporting this research and the Singapore National Research Foundation under NRF Award No. NRF-RF2010-03. A.C.S. acknowledges the Howard Hughes Medical Institute and the Harvard-MIT Division of Health Science and Technology for fellowship support. We acknowledge NSF (grant CHE-05180055) for funding.

Supplemental Information. The experimental procedures, nomenclatura, expansion of Figure 8, and the $J(\mathrm{~V})$ characteristics (DC measurement) of a $\mathrm{Ag}^{\mathrm{TS}}$ $\mathrm{SC}_{11} \mathrm{Fc}_{2} / / \mathrm{Ga}_{2} \mathrm{O}_{3} / \mathrm{EGaIn}$ junction that was stable during $J(\mathrm{~V})$ measurement of $\pm 2.0 \mathrm{~V}$.

This material is available free of charge via the Internet at http://pubs.acs.org.

\section{References}

\footnotetext{
${ }^{1}$ Nijhuis, C. A.; Reus, W. F.; Whitesides, G. M. J. Am. Chem. Soc. 2009, 31, 17816.

${ }^{2}$ Chiechi, R. C.; Weiss, E. A.; Dickey, M. D.; Whitesides, G. M. Angew. Chem., Int. Ed. 2008, $47,142$.

${ }^{3}$ Nijhuis, C. A.; Reus, W. F.; Whitesides, G. M. J. Am. Chem Soc. In press.
} 
${ }^{4}$ In the circuit shown in Figure 4, the polarity of the rectifier is reversed with respect the current density measurements, in which the electrodes were arranged such that the junctions passed current selectively at negative voltage, rather than positive voltage. For our demonstration of a half-wave rectifier, we have switched the polarity of the electrodes to conform to the convention of the community, that is, the current is allowed to pass at positive voltage.

${ }^{5}$ Aviram, A.; Ratner, M. A. Chem. Phys. Lett. 1974, 29, 277.

${ }^{6}$ Metzger, R. M. Acc. Chem. Res. 1999, 32, 950.

${ }^{7}$ Shumate, W. J.; Mattern, D. L.; Jaiswal, A.; Dixon, D. A.; White, T. R.; Burgess, J.; Honciuc, A.; Metzger, R. M. J. Phys. Chem. B 2006, 110, 11146.

${ }^{8}$ Ashwell, G. J.; Ewinton, J.; Robinson, B. J. Chem. Comm. 2006, 618.

${ }^{9}$ Ng, M. -K.; Lee, D. -C.; Yu, L. J. Am. Chem. Soc. 2002, 124, 11862.

${ }^{10}$ Peterson, I. R.; Vuillaume, D.; Metzger, R. M. J. Phys. Chem. A 2001, 105, 4702.

${ }^{11}$ Lenfant, S.; Krzeminski, C.; Delerue, C.; Allan, G.; Vuillaume, D. Nano Lett. 2003, 3, 741.

${ }^{12}$ Chabinyc, M. L.; Chen, X.; Holmlin, R. E.; Jacobs, H.; Skulason, H.; Frisbie, C. D.; Mujica, V.; Ratner, M. A.; Rampi, M. A.; Whitesides, G. M. J. Am. Chem. Soc. 2002, $124,11730$.

${ }^{13}$ Ashwell, G. J.; Urasinska-Wojcik, B.; Phillips, L. J. Angew. Chem. Int. Ed. 2010, 49, 3508.

${ }^{14}$ Gayathri, S. S.; Patnaik, A. Chem. Commun. 2006, 1977.

${ }^{15}$ Honciuc, A.; Jaiswal, A.; Gong, A.; Ashworth, K.; Spangler, C. W.; Peterson, I. R.; Dalton, L. R.; Metzger, R. M. J. Phys. Chem. B 2005, 109, 857. 
${ }^{16}$ Chen, X.; Jeon, Y. -M.; Jang, J. -W.; Qin, L.; Huo, F.; Wei, W.; Mirkin, C. A. J. Am.

Chem. Soc. 2008, 130, 8166.

${ }^{17}$ Böhme, T.; Simpson, C. D.; Müllen, K., Rabe, J. P. Chem. Eur. J. 2007, 13, 7349.

${ }^{18}$ Chen, X.; Jeon, Y. -M.; Jang, J. -W.; Qin, L.; Huo, F.; Wei, W.; Mirkin, C. A. J. Am.

Chem. Soc. 2008, 130, 8166.

${ }^{19}$ Metzger, R. M.; Chen, B.; Holpfner, U.; Lakshmikantham, M. V.; Vuillaume, D.;

Kawai, T.; Wu, X.; Tachibana, H.; Hughes, T. V.; Sakurai, H.; Baldwin, J. W.; Hosch,

C.; Cava, M. P.; Brehmer, L.; Ashwell, G. J. J. Am. Chem. Soc. 1997, 119, 10455.

${ }^{20}$ Salomon, A.; Boecking, T.; Chan, C. K.; Amy, F.; Girshevitz, O.; Cahen, D.; Kahn, A.

Phys. Rev. Lett. 2005, 95, 266807.

${ }^{21}$ Salomon, A.; Boecking, T.; Seitz, O.; Markus, T.; Amy, F.; Chan, C.; Zhao, W.;

Cahen, D.; Kahn, A. Adv. Mater. 2007, 19, 445.

${ }^{22}$ Salomon, A.; Böcking, T.; Gooding, J. J.; Cahen, D. Nano Lett. 2006, 6, 2873.

${ }^{23}$ Bang, G. S.; Chang, H.; Koo, J. -R.; Lee, T.; Advincula, R. C.; Lee, H. Small 2008, 4,1399 .

${ }^{24}$ Kim, T. -W.; Wang, G.; Lee, H.; Lee, T. Nanotechnology 2007, 18, 315204.

${ }^{25}$ Lau, C. N.; Stewart, D. R; Williams, R. S.; Bockrath, M. Nano Lett., 2004, 4, 569.

${ }^{26}$ Bebee, J. M.; Kushmerick, J. G. Appl. Phys. Lett. 2007, 90, 083117.

${ }^{27}$ Walker, A. V.; Tighe, T. B.; Cabarcos, O. M.; Reinard, M. D.; Haynie, B. C.; Uppili,

S.; Winograd, N.; Allara, D. L. J. Am. Chem. Soc. 2004, 126, 3954.

${ }^{28}$ Pierce, D. G.; Brusius, P. G. Microelectron. Reliab. 1997, 37, 1053.

${ }^{29}$ Krumbein S. J. IEEE Trans.Compon., Hybrids, Manuf. Technol. 1988, 11, 5.

${ }^{30}$ McCreery, R. L. Chem. Mater. 2004, 16, 4477. 
${ }^{31}$ Nijhuis, C. A.; Reus, W. F.; Barber, J.; Dickey, M. D.; Whitesides, G. M. Nano Lett. 2010, 10, 3611.

${ }^{32}$ Barr, T. L.; Seal, S. J. Vac. Sci. Technol. A 1995, 13, 1239.

${ }^{33}$ Reus, W. F.; Nijhuis, C. A.; Barber, J.; Mwangi, M.; Cademartiri, L.; Kim, C.; York, R. L.; Liu, X.; Whitesides, G. M. unpublished results.

${ }^{34}$ Lorenz, M. R.; Woods, J. F.; Gambino, R. J. J. Phys. Chem. Solids 1967, 28, 403.

${ }^{35}$ Müller-Meskamp, L.; Karthäuser, S.; Zandvliet, H. J. W.; Homberger, M.; Simon, U.; Waser, R. Small 2009, 5, 496.

${ }^{36}$ Liu, Y.; Offenhäusser, A.; Mayar, D. Phys. Status Solidi A 2010, 207, 891.

${ }^{37}$ Choi, S. H.; Kim, B. S.; Frisbie, C. F. Science 2008, 320, 1482.

${ }^{38}$ Beebe, J. M.; Kim, B.; Gadzuk, J. W.; Frisbie, D. C.; Kushmerick J.G. Phys. Rev. Lett. 2006, 97, 026801.

${ }^{39}$ Beebe, J. M.; Kim, B. S.; Frisbie, D. C.; Kushmerick J. G. ACS Nano, 2008, $2,827$.

${ }^{40}$ Engelkes, V. B.; Beebe, J. M.; Frisbie, C. D. J. Am. Chem. Soc. 2004, 126, 14287.

${ }^{41}$ Lindsay, S. M.; Ratner, M. A. Adv. Mater. 2007, 19, 23.

${ }^{42}$ Simmons, J. G. J. Appl. Phys. 1963, 34, 1793.

${ }^{43}$ Simmons, J. G. J. Appl. Phys. 1963, 34, 2581.

${ }^{44}$ McConnell, H. M. J. Chem. Phys. 1961, 508, 515.

45 Joachim, C.; Ratner, M. A. Proc. Natl. Acad, Sci. USA 2005, 102, 8801.

${ }^{46}$ Weiss, E. A.; Chiechi, R. C.; Kaufman, G. K.; Kriebel, J. K.; Li, Z.; Duati, M.; Rampi, M. A.; Whitesides G. M. J. Am. Chem. Soc. 2007, 129, 4336.

${ }^{47}$ Love, J. C.; Estroff, L. A.; Kriebel, J. K.; Nuzzo, R. G.; Whitesides, G. M. Chem. Rev. 2005, 105, 1103. 
${ }^{48}$ Richard C. Dorf The Electrical Engineering Handbook, CRC Press, Boca Raton, 1993.

${ }^{49}$ Paul, Clayton R. Fundamentals of Electric Circuit Analysis 2001, John Wiley \& Sons.

${ }^{50}$ Haag, R.; Rampi, M. A.; Holmlin, R. E.; Whitesides, G. M. J. Am. Chem. Soc. 1999, 121, 7895.

${ }^{51}$ McCreery, R. L.; Bergren, A. J. Adv. Mater. 2009, 21, 4303. 


\section{TOC Figure:}

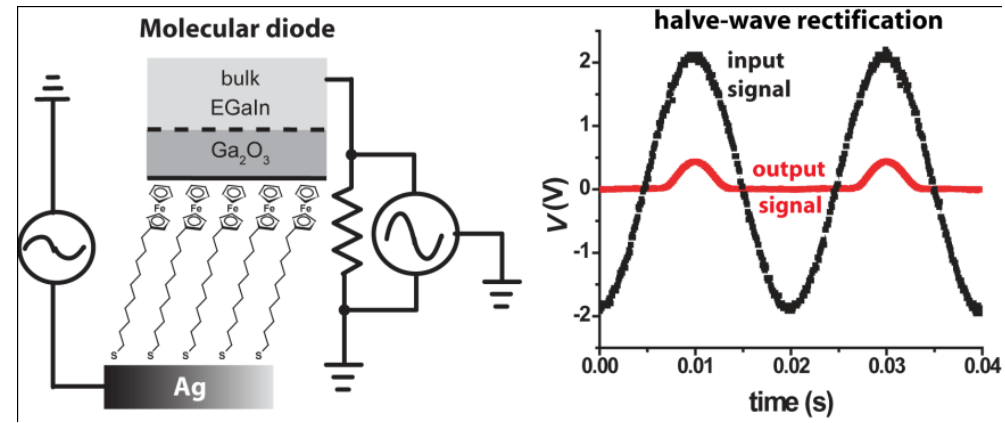

